\title{
Prediction of metabolisable energy concentrations of fresh-cut grass using digestibility data measured with non-pregnant non-lactating cows
}

\author{
Sokratis Stergiadis ${ }^{1}$, Michelle Allen ${ }^{2}$, Xianjiang Chen ${ }^{1,3}$, David Wills ${ }^{1}$ and Tianhai Yan $^{1 *}$ \\ ${ }^{1}$ Sustainable Agri-Food Sciences Division, Agriculture Branch, Agri-Food and Biosciences Institute, \\ Large Park, Hillsborough, County Down BT26 6DR, UK \\ ${ }^{2}$ Finance and Corporate Affairs Division, Biometrics and Information Systems Branch, Agri-Food and \\ Biosciences Institute, 18 a Newforge Lane, Belfast, County Antrim BT9 5PX, UK \\ ${ }^{3}$ State Key Laboratory of Grassland Agro-Ecosystems, College of Pastoral Agriculture Science and Technology, \\ Lanzhou University, Lanzhou 730020, People's Republic of China \\ (Submitted 21 October 2014 - Final revision received 26 February 2015 - Accepted 2 March 2015 - First published online 13 April 2015)
}

\section{Abstract}

Pasture-based ruminant production systems are common in certain areas of the world, but energy evaluation in grazing cattle is performed with equations developed, in their majority, with sheep or cattle fed total mixed rations. The aim of the current study was to develop predictions of metabolisable energy (ME) concentrations in fresh-cut grass offered to non-pregnant non-lactating cows at maintenance energy level, which may be more suitable for grazing cattle. Data were collected from three digestibility trials performed over consecutive grazing seasons. In order to cover a range of commercial conditions and data availability in pasture-based systems, thirty-eight equations for the prediction of energy concentrations and ratios were developed. An internal validation was performed for all equations and also for existing predictions of grass ME. Prediction error for ME using nutrient digestibility was lowest when gross energy (GE) or organic matter digestibilities were used as sole predictors, while the addition of grass nutrient contents reduced the difference between predicted and actual values, and explained more variation. Addition of N, GE and diethyl ether extract (EE) contents improved accuracy when digestible organic matter in DM was the primary predictor. When digestible energy was the primary explanatory variable, prediction error was relatively low, but addition of water-soluble carbohydrates, EE and acid-detergent fibre contents of grass decreased prediction error. Equations developed in the current study showed lower prediction errors when compared with those of existing equations, and may thus allow for an improved prediction of ME in practice, which is critical for the sustainability of pasture-based systems.

\section{Key words: Grass: Metabolisable energy: Digestibility: Prediction: Grazing: Maintenance feeding: Pasture-based ruminant} production

Grazed grass is a low-cost feed for cattle and offers an economic advantage to regions capable of long grazing seasons and high productivity of DM per hectare ${ }^{(1,2)}$. For this reason, pasture-based systems predominate ruminant production in certain countries, such as Ireland, New Zealand and parts of the $\mathrm{UK}^{(1-3)}$, thus enhancing the competitiveness of dairy and beef industry, preserving rural landscapes and improving the image of milk and meat production for consumers ${ }^{(4)}$.

However, fresh grass-based diets provide lower amounts of glucogenic nutrients ${ }^{(4)}$, than diets rich in concentrate feeds, and energy supply is challenging in grazing systems, because of the high contribution of pasture in the diets. Efficient assessment of the feeding value of grass is crucial in order to avoid excessive over-supply that would increase production costs, or under-supply that would reduce productivity. Developing tools to predict metabolisable energy (ME) in fresh grass may greatly improve profitability of pasture-based systems, with a $180000 \mathrm{MJ} /$ ha of $\mathrm{ME}$ being recommended as the production target ${ }^{(3)}$. Parameters such as digestible organic matter in DM (DOMD) and digestible energy (DE), predicted from contents of crude protein, neutral-detergent fibre (NDF), diethyl ether extract (EE), total digestible crude protein (tdCP), total digestible neutral-detergent fibre (tdNDF) and fatty acids of grass have been used to predict grass ME concentrations ${ }^{(4-6)}$

Abbreviations: ADF, acid-detergent fibre; DE, digestible energy; DMd, digestibility of DM; DOMD, digestible organic matter in DM; EE, diethyl ether extract; GE, gross energy; GEd, digestibility of gross energy; ME, metabolisable energy; MPE, mean prediction error; NDF, neutral-detergent fibre; NDFd, digestibility of neutral-detergent fibre; NRC, National Research Council; OMd, digestibility of organic matter; REML, residual maximum likelihood; tdCP, total digestible crude protein; tdNDF, total digestible neutral-detergent fibre; WSC, water-soluble carbohydrates.

* Corresponding author: T. Yan, fax +44 2892689594, email tianhai.yan@afbini.gov.uk 
In the current UK feeding system ${ }^{(6)}$, DOMD is used to predict grass ME content, but the different proportions of digestible nutrients in DOMD are not accounted for ${ }^{(7)}$. In addition, a number of limitations on the prediction of ME content of fresh grass raise concerns about the accuracy of ME predictions from grass nutrient contents and digestibility. The majority of the works on the prediction of ME content of grass (1) have been performed with diets based on conserved forages and concentrates, (2) they relied on prediction, instead of measurement, of methane emissions, and (3) they carried out the experiments with sheep instead of cattle ${ }^{(6,8)}$. Also, modern cows have higher production potential and maintenance requirements compared with those used to develop the existing energy systems ${ }^{(4,9)}$, and this may contribute further to the potential error when estimating grass ME contents. A previous work has reported discrepancies in current energy evaluations, when diets rich in good quality grass ( $>80 \%$ of DM intake) were $_{\text {offered }}{ }^{(9)}$. Consequently, the development of a quick and accurate assessment methodology for fresh grass ME contents, which would overcome these limitations and account for the various nutrients and their digestibility in fresh grass, seems to be a necessity for grazing cattle. The importance of using a greater range of grass nutrients in the evaluation of grass ME content has also been raised in previous reports ${ }^{(6)}$.

The objective of this study was therefore to develop predictions of grass energy contents, in particular ME, from grass nutrient contents and digestibility parameters for animals fed solely fresh-cut grass, which can be used for (1) the quick estimation of pasture ME contents under commercial conditions, e.g. using routinely available near-IR spectroscopy data and (2) the revision of existing feeding tables used in the development of grazing ruminant diets.

\section{Experimental design and methods}

The present study was performed under the regulations of the Department of Health, Social Services, and Public Safety of Northern Ireland, in line with the Animal (Scientific Procedures) Act $1986^{(10)}$. In total, 1392 records collected over three digestibility trials from consecutive grazing seasons and 3 -d averaged data ( $n$ 464) were used in the dataset to develop prediction equations. Grass used was grown on ten swards in total representing different years (2007, 2008, 2009), harvest seasons (primary growth, first regrowth, second regrowth), maturity stages (3-9 weeks) and combination of ryegrass varieties (Aberstar, Aberzest, Fetione, Magella, Merbo, Merlinda and Spelga). In 2007, a first regrowth and a second regrowth swards were fertilised with 8 and $54 \mathrm{~kg} \mathrm{~N} /$ ha respectively. In 2008, two primary growth swards were fertilised with 45 and $70 \mathrm{~kg} \mathrm{~N} / \mathrm{ha}$, two first regrowth swards with 40 and $65 \mathrm{~kg} \mathrm{~N} / \mathrm{ha}$ and two second regrowth swards with 35 and $60 \mathrm{~kg} \mathrm{~N} / \mathrm{ha}$ respectively. In 2009, two primary growth swards were fertilised with $59 \mathrm{~kg}$ $\mathrm{N} /$ ha. Sward characteristics and management throughout the 3 -year experiment have been described in detail by Stergiadis et $a l^{(11)}$. In total, eight groups of four cows (plus one substitute cow in 2008, $n$ 33) were used to assess energy concentrations of fresh-cut grass. In 2007, two groups of four cows ( $n$ 8) assessed early and late maturity grass from a primary and a secondary growth swards, with the group assessing early maturity in the first regrowth sward being used to assess late maturity in the second regrowth sward and vice versa for the second group of cows. In 2008, four groups of four cows (plus one substitute cow, $n$ 17) were used to assess early and late maturity swards during primary growth, first regrowth and second regrowth swards, with either medium (35-45 kg N/ha) or high (60-70 kg N/ha) N fertiliser input. Two groups were fed early maturity grass and two groups late maturity grass respectively throughout the experiment, while the other groups were swapping between early and late maturity grass over the three harvest dates. The two groups within the same maturity treatment received grass from medium or high fertiliser input, and they were swapped within this treatment between the three harvest dates. In 2009, two groups of four cows ( $n$ 8) assessed early and late maturity grass respectively, from a primary growth sward. For each group, daily recording of feed intake and total collection of faeces and urine were carried out for three consecutive weeks, following an adaptation period of solely fresh grass diets of at least two weeks. Detailed experimental design and sample collection and analytical procedures, were presented by Stergiadis et al. ${ }^{(11,12)}$. Details on animal data, grass chemical composition, nutrient digestibility and energy inputs/outputs and concentrations recorded over the 3 years of the present experiment are given in Table 1.

As a result of the contrasting sward characteristics and management, a large diversity of grass nutrient composition was observed; for example, grass $\mathrm{N}$, water-soluble carbohydrates (WSC) and NDF contents ranged between 10.7-38.1, 70-272, and 413-601 g/kg DM, respectively. Similarly, gross energy (GE), DE and ME contents of grass ranged between 16.9-19.1, $11 \cdot 8-16 \cdot 7$ and $9 \cdot 0-14 \cdot 1 \mathrm{MJ} / \mathrm{kg} \mathrm{DM}$, respectively. Concentrations of DOMD were between 0.636 and $0.851 \mathrm{~kg} / \mathrm{kg}$ DM. Concentrations of DE, DOMD and DM, $\mathrm{N}, \mathrm{GE}, \mathrm{NDF}$, acid-detergent fibre (ADF) and organic matter digestibilities were measured in metabolism units with non-pregnant non-lactating dairy cows fed at maintenance energy level. The ME concentration was estimated by extracting measured urine energy output and predicted methane energy output from measured DE intake. Methane emissions from all individual cows were also measured for two to three periods $(1 \mathrm{~d}$ for adaptation and $2 \mathrm{~d}$ for measurements in each period) in the 2007 trials of the present study ( $n 40$ data). The equations used to predict methane energy output from grass ADF, GE, DM, and EE contents $\left(R^{2} 0 \cdot 77\right)$ were previously presented by Yan \& Mayne ${ }^{(13)}$.

In order to assess feed quality of grass for immediate development of accurate diets that meet maintenance energy requirements, fresh grass DM concentration was estimated by microwaving at full power for 3-5 min. Grass ME was then predicted by near-IR spectroscopy ${ }^{(14)}$, using a NIRS $^{\text {TM }}$ 5000/ 6500 Feed and Forage Analyser (FOSS), and ME concentration was estimated using the average value of samples collected daily over the previous two consecutive days. Maintenance ME requirements were estimated as described by Agnew et $a l .{ }^{(15)}\left(0.65 \mathrm{MJ} / \mathrm{kg}\right.$ of metabolic body weight, $\left.\mathrm{kg}^{0.75}\right)$. 
Table 1. Animal data, grass chemical composition ( $n$ 116), nutrient digestibility and energy intakes/outputs and concentrations ( $n$ 464) recorded over 3 years

\begin{tabular}{|c|c|c|c|c|c|}
\hline Parameters assessed & Mean & SD & $\mathrm{CV}$ & Min & Max \\
\hline \multicolumn{6}{|l|}{ Animal data } \\
\hline Body weight $(\mathrm{kg})$ & 548 & $61 \cdot 0$ & $11 \cdot 1$ & 421 & 722 \\
\hline Body condition score $(1-5)$ & $2 \cdot 6$ & 0.33 & $12 \cdot 7$ & 1.5 & 3.5 \\
\hline \multicolumn{6}{|l|}{ Grass chemical composition ( $\mathrm{g} / \mathrm{kg} \mathrm{DM}$ ) } \\
\hline DM (g/kg fresh) & 176 & 46.9 & $24 \cdot 0$ & 103 & 324 \\
\hline Ash & 80 & $16 \cdot 9$ & $21 \cdot 0$ & 40 & 110 \\
\hline $\mathrm{N}$ & $22 \cdot 6$ & 6.71 & 29.6 & $10 \cdot 7$ & $38 \cdot 1$ \\
\hline Acid-detergent fibre & 267 & $37 \cdot 2$ & $13 \cdot 9$ & 207 & 362 \\
\hline Neutral-detergent fibre & 503 & $37 \cdot 0$ & $7 \cdot 3$ & 413 & 601 \\
\hline Water-soluble carbohydrates & 158 & 47.9 & $30 \cdot 1$ & 70 & 272 \\
\hline Diethyl ether extract & 30 & $7 \cdot 4$ & 24.7 & 16 & 55 \\
\hline \multicolumn{6}{|l|}{ Nutrient digestibility (g/g) } \\
\hline DM & 0.801 & 0.0412 & $5 \cdot 1$ & 0.642 & 0.900 \\
\hline $\mathrm{N}$ & 0.732 & 0.0881 & $11 \cdot 8$ & 0.395 & 0.891 \\
\hline $\mathrm{GE}(\mathrm{MJ} / \mathrm{MJ})$ & 0.790 & 0.0433 & 5.4 & 0.650 & 0.900 \\
\hline Acid-detergent fibre & 0.797 & 0.0466 & $5 \cdot 8$ & 0.643 & 0.898 \\
\hline Neutral-detergent fibre & 0.803 & 0.0478 & 5.9 & 0.623 & 0.899 \\
\hline Organic matter & 0.828 & 0.0395 & 4.7 & 0.698 & 0.910 \\
\hline Digestible organic matter in DM & 0.762 & 0.0348 & 4.5 & 0.636 & 0.851 \\
\hline \multicolumn{6}{|l|}{ GE intakes/outputs (MJ/d) } \\
\hline Intake & 112.5 & 13.65 & $12 \cdot 1$ & 73.4 & $166 \cdot 3$ \\
\hline Output in faeces & 23.7 & 6.41 & $27 \cdot 0$ & $10 \cdot 9$ & 45.4 \\
\hline Output in urine & $5 \cdot 0$ & 1.75 & 34.8 & 1.2 & $12 \cdot 0$ \\
\hline Output in methane ${ }^{*}$ & 10.5 & $2 \cdot 18$ & $20 \cdot 8$ & $2 \cdot \overline{8}$ & $17 \cdot 0$ \\
\hline \multicolumn{6}{|l|}{ Energy concentrations (MJ/kg DM) } \\
\hline GE $(\mathrm{MJ} / \mathrm{kg} \mathrm{DM})$ & $18 \cdot 3$ & 0.38 & $2 \cdot 0$ & 16.9 & $19 \cdot 1$ \\
\hline $\mathrm{DE}$ & 14.5 & 0.92 & $6 \cdot 3$ & $11 \cdot 8$ & $16 \cdot 7$ \\
\hline $\mathrm{ME}$ & $12 \cdot 0$ & 0.74 & $6 \cdot 1$ & $9 \cdot 0$ & $14 \cdot 1$ \\
\hline $\mathrm{DE}: \mathrm{GE}$ & 0.790 & 0.0433 & 5.5 & 0.650 & 0.900 \\
\hline ME:GE & 0.653 & 0.0402 & $6 \cdot 0$ & 0.476 & 0.771 \\
\hline
\end{tabular}

Min, minimum value observed; Max, maximum value observed; GE, gross energy; DE, digestible energy; ME, metabolisable energy.

* Methane emissions were predicted from equations developed during the first year of the present study as in Yan \& Mayne ${ }^{(13)}$.

\section{Statistical analysis}

Analyses of data were carried out in GenStat ${ }^{(16)}$. The residual diagnostics were assessed using normality plots and were found to be acceptable. Regression equations were developed using residual maximum likelihood (REML) ${ }^{(17,18)}$, so that the potential random effects of cow, field, year, harvest date, fertiliser input, maturity stage and grass variety could be accounted for. Linear regression relationships were established, where the responses were $\mathrm{DE}, \mathrm{ME}$ and ratios of DE:GE or ME:GE; the fixed terms were (1) digestibilities of $\mathrm{N}(\mathrm{Nd})$, gross energy (GEd), NDF (NDFd), ADF (ADFd), DM (DMd) and organic matter (OMd) and DOMD, (2) grass contents of N, GE, WSC, EE, NDF, ADF and ash, and (3) tdCP and tdNDF; they were all developed either in univariate (equation 1) or multivariate (equation 2 ) linear models.

$$
\begin{gathered}
Y=a+b x \\
Y=a+b_{1} x_{1}+b_{2} x_{2}+b_{3} x_{3}+\ldots+b_{n} x_{n} .
\end{gathered}
$$

Total digestible amounts for each nutrient $(\mathrm{kg} / \mathrm{kg} \mathrm{DM})$ were generated, separately for $\mathrm{N}$ and NDF, by multiplying grass nutrient content $(\mathrm{kg} / \mathrm{kg} \mathrm{DM})$, measured by wet chemistry analysis, with nutrient digestibility $(\mathrm{kg} / \mathrm{kg})$, which represents the proportion of ingested nutrients not excreted in faeces, measured during the digestibility experiments. Candidate nested models of the random variation, with the same fixedeffect model, were compared using the deviance. The change in deviance between the nested random models was assessed using $\chi^{2}$ with the $\mathrm{df}$ given by the difference in $\mathrm{df}$ of the two models. The significance of the fixed terms was assessed using the Wald statistic. The squared correlation of the response and the fitted values $\left(R^{2}\right)$ to represent the amount of variability explained was also derived.

An internal evaluation, using the methods of Yan et al. ${ }^{(19)}$ and Stergiadis $e t a l .{ }^{(12)}$ was performed to validate all prediction equations developed in the present study (Tables 2-5). The whole dataset ( $n$ 464) was divided into two sub-datasets of $n 309$ (two-thirds of the total data) and $n 155$ (one-third of the total data). The former dataset was used to develop equations (Table 6), applying models of the same random and fixed factors combinations to those produced from the whole dataset, while the latter was used to evaluate the precision of these new equations (Table 7). This was assessed by using the meansquare prediction error (MSPE) technique (equation 3).

$$
\text { MSPE }=\frac{1}{n} \sum(P-A)^{2},
$$


Table 2. Univariate linear prediction of energy contents and ratios in fresh grass (with non-pregnant non-lactating cows fed at maintenance energy level, $n 464$ ), using nutrient digestibility parameters

\begin{tabular}{|c|c|c|c|}
\hline $\begin{array}{l}\text { Equations for the prediction } \\
\text { of } D E, M E, D E: G E \text { and } M E: G E^{*}\end{array}$ & $R^{2}$ & MPE† & Equat \\
\hline $\mathrm{DE}=-0.420_{(0.399)}+18.58_{(0.39)} \mathrm{DMd}$ & 0.91 & 0.036 & 1(a) \\
\hline $\mathrm{DE}=-4.079_{(0.343)}+22 \cdot 45_{(0.38)} \mathrm{OMd}$ & 0.95 & 0.030 & $1(\mathrm{~b})$ \\
\hline $\mathrm{DE}=-2 \cdot 445_{(0.481)}+22 \cdot 53_{(0.43)} \mathrm{DOMD}$ & 0.93 & 0.042 & 1(c) \\
\hline $\mathrm{ME}=-0.432_{(0.495)}+15.44_{(0.43)} \mathrm{DMd}$ & 0.84 & 0.050 & $2(a)$ \\
\hline $\mathrm{ME}=-3.455_{(0.464)}+18.44_{(0.49)} \mathrm{OMd}$ & 0.86 & 0.046 & 2(b) \\
\hline $\mathrm{ME}=-2.238_{(0.474)}+18.52_{(0.53)} \mathrm{DOMD}$ & 0.84 & 0.054 & 2(c) \\
\hline $\mathrm{ME}=-1 \cdot 163_{(0.380)}+16 \cdot 42_{(0.41)} \mathrm{GEd}$ & 0.87 & 0.043 & 2(d) \\
\hline $\mathrm{DE}: \mathrm{GE}=0.035_{(0.016)}+0.941_{(0.014)} \mathrm{DMd}$ & 0.96 & 0.029 & $3(a)$ \\
\hline $\mathrm{DE}: \mathrm{GE}=-0.141_{(0.007)}+1.126_{(0.008)} \mathrm{OMd}$ & 0.99 & 0.010 & $3(\mathrm{~b})$ \\
\hline $\mathrm{DE}: \mathrm{GE}=-0.075_{(0.016)}+1 \cdot 137_{(0.013)} \mathrm{DOMD}$ & 0.95 & 0.029 & $3(c)$ \\
\hline ME:GE $=0.019_{(0.033)}+0.789_{(0.029)} \mathrm{DMd}$ & 0.77 & 0.061 & $4(\mathrm{a})$ \\
\hline $\mathrm{ME}: \mathrm{GE}=-0.117_{(0.032)}+0.928_{(0.033)} \mathrm{OMd}$ & 0.78 & 0.053 & 4(b) \\
\hline $\mathrm{ME}: \mathrm{GE}=-0.056_{(0.032)}+0.921_{(0.036)} \mathrm{DOMD}$ & 0.75 & 0.063 & $4(c)$ \\
\hline ME:GE $=0.005_{(0.028)}+0.818_{(0.028)} \mathrm{GEd}$ & 0.78 & 0.052 & 4(d) \\
\hline
\end{tabular}

$\mathrm{DE}$, grass digestible energy content; $\mathrm{ME}$, grass metabolisable energy content; $\mathrm{GE}$ grass gross energy content; $R^{2}$, pseudo-correlation coefficient; MPE, mean prediction error; DMd, DM digestibility; OMd, organic matter digestibility; DOMD, digestible organic matter in DM; GEd, gross energy digestibility.

* Units: MJ/kg DM for DE, ME and GE; $\mathrm{kg} / \mathrm{kg}$ for DMd and OMd; $\mathrm{kg} / \mathrm{kg}$ DM for DOMD; MJ/MJ for GEd. Values in subscript parentheses represent standard error of means. The effect of all explanatory variables was significant according to the Wald statistic $(\mathrm{Fpr}<0.05)$. A combination of potential random effects of cow, field, year, harvest date, fertiliser input, maturity stage and grass variety was accounted for accordingly for each predicted variable.

TMPE derived from an internal validation with new equations, listed in Table 6 , which were developed from two-thirds of the whole dataset and by using the exact model presented in the current table; the new equations were validated against the remaining one-third of the whole dataset.

where $P$ and $A$ are the predicted and actual values, respectively, and $n$ is the number of paired values for $P$ and $A$ compared. Mean prediction error (MPE) was used to describe the prediction accuracy (equation 4):

$$
\mathrm{MPE}=\sqrt{M S P E} /\left(\sum A / n\right) .
$$

The same one-third of the present dataset was also used to validate equations of Givens et al. ${ }^{(20)}$, Terry et al. ${ }^{(21)}$, National Research Council (NRC) ${ }^{(5)}$ and Agricultural and Food Research Council $^{(6)}$ for the prediction of ME concentrations, using digestibility and grass chemical composition parameters or DE (Table 8). In addition, Lin's concordance correlation coefficient was generated in order to quantify the agreement between in vivo measured $\mathrm{ME}$ and $\mathrm{ME}$ predicted by equations developed in the present (Table 7) or previously published $^{(5,20,21)}$ (Table 8) studies, and part of this analysis is presented in Figs. 1-3.

\section{Results}

Prediction of digestible energy and metabolisable energy contents of grass using nutrients' digestibility as sole predictor

When the relations between energy and digestibility parameters were investigated using REML analysis, (1) contents of DE and ME and ratios of DE:GE and ME:GE in grass were positively related to DMd, OMd and DOMD and (2) there was a significant effect of DMd, OMd, DOMD and GEd according to the Wald statistic (Table 2; equations 1(a)-(c), 2(a)-(d), 3(a)-(c), and 4(a)-(d)). Relations of ME with nutrient digestibility parameters are graphically presented in online Supplementary Fig. S1.

For the prediction of DE or the DE:GE ratio, using OMd as sole explanatory variable showed the lowest MPE, using DOMD showed the highest MPE and using DMd showed intermediate values, although in case of the prediction of DE:GE the MPE for equations using DMd or DOMD was similar. Using GEd showed the lowest MPE, when DMd,

Table 3. Multivariate linear prediction of energy contents and ratios in fresh grass (with non-pregnant non-lactating cows fed at maintenance energy level, $n 464$ ), using nutrient digestibility and grass chemical composition parameters

\begin{tabular}{|c|c|c|c|}
\hline Equations for the prediction of DE, ME, DE:GE and ME:GE* & $R^{2}$ & MPE† & Equation \\
\hline $\mathrm{DE}=1.807_{(0.441)}+16.67_{(0.36)} \mathrm{DMd}+16.92_{(470)} \mathrm{N}+19.47_{(3.10)} \mathrm{EE}-3.578_{(0.599)}$ ADF $-9.518_{(1.477)}$ Ash & 0.94 & 0.028 & 1(d) \\
\hline $\mathrm{DE}=-3.041_{(0.313)}+20.43_{(0.34)} \mathrm{OMd}+24.38_{(3.52)} \mathrm{N}+1.389_{(0.548)} \mathrm{WSC}+17.31_{(2.58)} \mathrm{EE}-8.065_{(1.166)}$ Ash & 0.96 & 0.024 & $1(\mathrm{e})$ \\
\hline $\mathrm{DE}=-2 \cdot 779_{(0.286)}+21 \cdot 14_{(0.37)} \mathrm{DOMD}+26 \cdot 25_{(3.50)} \mathrm{N}+20 \cdot 55_{(2 \cdot 67)} \mathrm{EE}$ & 0.95 & 0.021 & $1(\mathrm{f})$ \\
\hline $\mathrm{ME}=0.751_{(0.591)}+16.01_{(0.45)} \mathrm{DMd}-40.56_{(437)} \mathrm{N}-3.354_{(0.759)} \mathrm{ADF}$ & 0.86 & 0.064 & 2(e) \\
\hline $\mathrm{ME}=-3 \cdot 590_{(0.413)}+19 \cdot 70_{(0.46)} \mathrm{OMd}-38 \cdot 83_{(3.45)} \mathrm{N}$ & 0.88 & 0.051 & $2(f)$ \\
\hline $\mathrm{ME}=1.964_{(1.255)}+19.59_{(0.53)} \mathrm{DOMD}-22.96_{(5.34)} \mathrm{N}-0.261_{(0.072)} \mathrm{GE}+9.918_{(3.998)} \mathrm{EE}$ & 0.86 & 0.060 & $2(\mathrm{~g})$ \\
\hline $\mathrm{ME}=1.047_{(1.116)}+17.46_{(0.41)} \mathrm{GEd}-31.72_{(4.36)} \mathrm{N}-0.145_{(0.058)} \mathrm{GE}+2.223_{(1.072)} \mathrm{NDF}-2 \cdot 735_{(1.106)}$ ADF & 0.90 & 0.050 & $2(\mathrm{~h})$ \\
\hline $\mathrm{DE}: \mathrm{GE}=0.079_{(0.018)}+0.919_{(0.014)} \mathrm{DMd}-0.096_{(0.023)} \mathrm{ADF}$ & 0.96 & 0.027 & 3(d) \\
\hline $\mathrm{DE}: \mathrm{GE}=-0.179_{(0.011)}+1.136_{(0.009)} \mathrm{OMd}+0.057_{(0.011)} \mathrm{NDF}$ & 0.99 & 0.009 & $3(e)$ \\
\hline $\mathrm{DE}: \mathrm{GE}=-0.042_{(0.020)}+1.119_{(0.016)} \mathrm{DOMD}+0.679_{(0.129)} \mathrm{N}-0.173_{(0.036)} \mathrm{NDF}+0.199_{(0.038)} \mathrm{ADF}$ & 0.96 & 0.026 & $3(f)$ \\
\hline ME:GE $=0.671_{(0.071)}+0.881_{(0.025)} \mathrm{DMd}-2.102_{(0.279)} \mathrm{N}-0.035_{(0.004)} \mathrm{GE}-0.156_{(0.044)} \mathrm{ADF}$ & 0.87 & 0.060 & $4(e)$ \\
\hline ME:GE $=0.485_{(0.059)}+1.076_{(0.025)} \mathrm{OMd}-2.017_{(0.233)} \mathrm{N}-0.037_{(0.003)} \mathrm{GE}$ & 0.88 & 0.050 & $4(f)$ \\
\hline ME:GE $=0.805_{(0.068)}+1.095_{(0.028)} \mathrm{DOMD}-1.212_{(0.292)} \mathrm{N}-0.053_{(0.004)} \mathrm{GE}+0.525_{(0.218)} \mathrm{EE}$ & 0.86 & 0.061 & $4(\mathrm{~g})$ \\
\hline ME:GE $=0.733_{(0.055)}+0.959_{(0.021)} \mathrm{GEd}-1.523_{(0.217)} \mathrm{N}-0.044_{(0.003)} \mathrm{GE}$ & 0.90 & 0.047 & $4(\mathrm{~h})$ \\
\hline
\end{tabular}

$\mathrm{DE}$, grass digestible energy content; ME, grass metabolisable energy content; GE, grass gross energy content; $R^{2}$, pseudo correlation coefficient; MPE, mean prediction error; DMd, DM digestibility; N, grass nitrogen content; EE, grass diethyl ether extract content; ADF, grass acid-detergent fibre content; OMd, organic matter digestibility; WSC, grass water-soluble carbohydrate content; DOMD, digestible organic matter in DM; GEd, gross energy digestibility; NDF, grass neutral-detergent fibre content.

*Units: MJ/kg DM for DE, ME and GE; kg/kg for DMd and OMd; kg/kg DM for N, EE, ADF, Ash, WSC, DOMD and NDF; MJ/MJ for GEd. Values in subscript parentheses represent standard error. The effect of all explanatory variables was significant according to the Wald statistic (Fpr $<0.05)$. A combination of potential random effects of cow, field, year, harvest date, fertiliser input, maturity stage and grass variety was accounted for accordingly for each predicted variable.

† MPE derived from an internal validation with new equations, listed in Table 6, which were developed from two-thirds of the whole dataset and by using the exact model presented in the current table; the new equations were validated against the remaining one-third of the whole dataset. 
Table 4. Univariate and multivariate linear prediction of metabolisable energy (ME) content in fresh grass (with non-pregnant non-lactating cows fed at maintenance energy level, $n$ 464), using digestible energy (DE) and grass chemical composition parameters

\begin{tabular}{lccc}
\hline Equations for the prediction of ME* & $R^{2}$ & MPE† & Equation \\
\hline$M E=1.464_{(0.434)}+0.723_{(0.024)} \mathrm{DE}$ & 0.79 & 0.051 & $2(\mathrm{i})$ \\
$\mathrm{ME}=0.927_{(0.360)}+0.853_{(0.023)} \mathrm{DE}-49.20_{(5.20)} \mathrm{N}-10.75_{(3.97)} \mathrm{EE}$ & 0.85 & 0.052 & $2(\mathrm{j})$ \\
$\mathrm{ME}=1.019_{(0.369)}+0.836_{(0.023)} \mathrm{DE}-57.67_{(4.18)} \mathrm{N}$ WSC $-25.07_{(4.16)} \mathrm{EE}+3.262_{(0.814)}$ ADF & 0.85 & 0.054 & $2(\mathrm{k})$ \\
$\mathrm{ME}=-0.821_{(0.600)}+0.839_{(0.027)} \mathrm{DE}+2.455_{(0.887)}$ WSC & 0.047 & $2(\mathrm{l})$ \\
$\mathrm{ME}=-1.541_{(0.617)}+0.780_{(0.026)} \mathrm{DE}+5.449_{(0.743)}$ WSC $+4.403_{(0.817)} \mathrm{ADF}$ & 0.81 & 0.051 & $2(\mathrm{~m})$ \\
\hline
\end{tabular}

$R^{2}$, pseudo correlation coefficient; MPE, mean prediction error; $\mathrm{N}$, grass nitrogen content; $\mathrm{EE}$, grass diethyl ether extract content; WSC, grass water-soluble carbohydrate content; ADF, grass acid-detergent fibre content.

* Units: MJ/kg DM for ME and DE; $\mathrm{kg} / \mathrm{kg}$ DM for N, EE, WSC and ADF. Values in subscript parentheses represent standard error. The effect of all explanatory variables was significant according to the Wald statistic $(\mathrm{Fpr}<0.05)$. A combination of potential random effects of cow, field, year, harvest date, fertiliser input, maturity stage and grass variety was accounted for accordingly for each predicted variable.

† MPE derived from an internal validation with new equations, listed in Table 6, which were developed from two-thirds of the whole dataset and by using the exact model presented in the current table; the new equations were validated against the remaining one-third of the whole dataset.

OMd, DOMD or GEd was used as the sole explanatory variable for the prediction of ME and ME:GE ratio. Among the other three sole predictors, and similarly for the prediction of DE, OMd showed the lowest MPE, DOMD the highest MPE and DMd intermediate values.

\section{Prediction of digestible energy and metabolisable energy contents of grass using nutrients' concentrations and digestibility}

When the relations between energy parameters and nutrient concentrations and digestibilities were investigated, using REML analysis, the effects of (1) DMd, OMd, DOMD and GEd, and (2) grass N, EE, ADF, ash, WSC, GE and NDF contents on the prediction of energy parameters were significant, in various models, according to the Wald statistic (Table 3; equations 1(d)-(f), 2(e)-(h), 3(d)-(f), 4(e)-(h)). MPE was found generally reduced, when chemical composition variables of grass were added to prediction models of DE, ME, DE:GE and ME:GE that were developed by solely using DMd, OMd, DOMD or GEd as explanatory variable. The only exceptions were the higher MPEs for the predictions of ME when chemical composition parameters of grass were added to models using DMd, OMd or GEd as primary predictor.

MPE was shown as the lowest, when DE contents of grass were predicted from DMd, OMd or DOMD and chemical composition of grass, using a model with DOMD in which the Wald statistic identified as well $\mathrm{N}$ and EE contents of grass as significant explanatory variables. Using OMd as primary predictor, in conjunction with N, WSC, EE, and ash, showed lower MPE than using DMd as primary predictor with N, EE, $\mathrm{ADF}$ and ash.

MPE was shown as the lowest, when ME contents of grass were predicted from DMd, OMd, DOMD or GEd and grass chemical composition, using a model with GEd, in which the Wald statistic identified as well N, GE, NDF and ADF as significant predictors. However, this MPE was still higher when compared with the equation using GEd as the sole predictor. A slightly higher MPE was found when OMd was used as primary predictor, with only $\mathrm{N}$ being identified (by the Wald statistic) as significant additional variable. When DMd was used as primary predictor, $\mathrm{N}$ and ADF were also found as significant explanatory variables in the model, but using DOMD instead of DMd, was followed by a substitution of ADF with GE and EE in the model according to the Wald statistic, and the latter equation showed lower MPE.

MPE was shown as the lowest, when grass DE:GE ratio was predicted from DMd, OMd or DOMD and grass chemical composition, using a model with OMd as primary predictor; the Wald statistic identified NDF as significant additional predictor in the same model. When DMd or DOMD was used as primary predictor, MPE was only slightly lower for

Table 5. Multivariate linear prediction of energy contents in fresh grass (with non-pregnant non-lactating cows fed at maintenance energy level, $n$ 464), using total digestible crude protein (tdCP), total digestible neutral-detergent fibre (tdNDF) and grass chemical composition parameters

\begin{tabular}{|c|c|c|c|}
\hline Equations for the prediction of $\mathrm{DE}$ and $\mathrm{ME}^{*}$ & $R^{2}$ & MPE† & Equation \\
\hline $\mathrm{DE}=7 \cdot 255_{(0.580)}+0 \cdot 176_{(0.010)} \mathrm{tdCP}+0.133_{(0.011)} \mathrm{tdNDF}$ & 0.75 & 0.080 & $1(\mathrm{~g})$ \\
\hline$D E=2.802_{(0.644)}+0.244_{(0.011)} t d C P+0.166_{(0.010)} t d N D F+15.13_{(0.95)} W S C$ & 0.82 & 0.058 & $1(\mathrm{~h})$ \\
\hline $\mathrm{DE}=2.061_{(0.609)}+0.214_{(0.012)} \mathrm{tdCP}+0.166_{(0.010)} \mathrm{tdNDF}+15.99_{(0.91)} \mathrm{WSC}+30.62_{(5.09)} \mathrm{EE}$ & 0.82 & 0.048 & $1(\mathrm{i})$ \\
\hline $\mathrm{ME}=5.478_{(0.614)}+0.061_{(0.011)} \mathrm{tdCP}+0.145_{(0.012)} \mathrm{tdNDF}$ & 0.58 & 0.087 & $2(\mathrm{n})$ \\
\hline $\mathrm{ME}=1.361_{(0.674)}+0.123_{(0.012)} \mathrm{tdCP}+0.176_{(0.011)} \mathrm{tdNDF}+14 \cdot 37_{(1.10)} \mathrm{WSC}$ & 0.66 & 0.078 & 2(0) \\
\hline
\end{tabular}

$\mathrm{DE}$, grass digestible energy content; ME, grass metabolisable energy content; $R^{2}$, pseudo correlation coefficient; MPE, mean prediction error; WSC, grass water-soluble carbohydrate content; EE, grass diethyl ether extract content.

* Units: MJ/kg DM for DE and ME; g/100g DM for tdCP and tdNDF; kg/kg DM for WSC and EE. Values in subscript parentheses represent standard error. The effect of all explanatory variables was significant according to the Wald statistic (Fpr $<0.05)$. A combination of potential random effects of cow, field, year, harvest date, fertiliser input, maturity stage and grass variety was accounted for accordingly for each predicted variable.

† MPE derived from an internal validation with new equations, listed in Table 6, which were developed from two-thirds of the whole dataset and by using the exact model presented in the current table; the new equations were validated against the remaining one-third of the whole dataset. 
Table 6. Internal validation: univariate and multivariate linear prediction of energy contents and ratios in fresh grass (with non-pregnant non-lactating cows fed at maintenance energy level, $n 464)$, from nutrient digestibility, grass chemical composition parameters, digestible energy (DE), total digestible crude protein (tdCP) and total digestible neutral-detergent fibre (tdNDF), using two-thirds of the whole dataset $(n$ 309)

\begin{tabular}{|c|c|c|c|c|}
\hline Equation & $\begin{array}{l}\text { Original } \\
\text { equation* }\end{array}$ & Equations for the prediction of $\mathrm{DE}, \mathrm{ME}, \mathrm{DE}: \mathrm{GE}$ and $\mathrm{ME}: \mathrm{GE} \dagger$ & $R^{2}$ & MPE \\
\hline A & (1a) & $\mathrm{DE}=-0.712_{(0.456)}+18.96_{(0.48)} \mathrm{DMd}$ & 0.90 & 0.036 \\
\hline B & (1b) & $\mathrm{DE}=-4 \cdot 248_{(0.390)}+22 \cdot 66_{(0.45)} \mathrm{OMd}$ & 0.94 & 0.030 \\
\hline C & (1c) & $\mathrm{DE}=-2 \cdot 646_{(0.545)}+22 \cdot 81_{(0.55)} \mathrm{DOMD}$ & 0.92 & 0.042 \\
\hline D & (1d) & $\mathrm{DE}=1.345_{(0.522)}+16.93_{(0.47)} \mathrm{DMd}+18.66_{(6.05)} \mathrm{N}+15.88_{(4.03)} \mathrm{EE}-3.442_{(0.763)} \mathrm{ADF}-5.892_{(1.970)}$ Ash & 0.93 & 0.028 \\
\hline $\mathrm{E}$ & (1e) & $\mathrm{DE}=-3 \cdot 287_{(0.393)}+20 \cdot 46_{(0.44)} \mathrm{OMd}+25 \cdot 91_{(4.53)} \mathrm{N}+1.836_{(0.655)} \mathrm{WSC}+14.71_{(3.42)} \mathrm{EE}-5.437_{(1.527)}$ Ash & 0.96 & 0.024 \\
\hline $\mathrm{F}$ & $(1 \mathrm{f})$ & $\mathrm{DE}=-2 \cdot 664_{(0.363)}+20 \cdot 92_{(0.48)} \mathrm{DOMD}+27 \cdot 26_{(462)} \mathrm{N}+20 \cdot 67_{(3.54)} \mathrm{EE}$ & 0.95 & 0.021 \\
\hline G & (1g) & $\mathrm{DE}=7.093_{(0.636)}+0.195_{(0.013)} \mathrm{tdCP}+0.132_{(0.013)} \mathrm{tdNDF}$ & 0.75 & 0.080 \\
\hline $\mathrm{H}$ & (1h) & $\mathrm{DE}=2.672_{(0.755)}+0.252_{(0.014)} \mathrm{tdCP}+0.167_{(0.012)} \mathrm{tdNDF}+15.01_{(1.18)} \mathrm{WSC}$ & $0 \cdot 81$ & 0.058 \\
\hline I & (1i) & $\mathrm{DE}=1.964_{(0.722)}+0.217_{(0.015)} \mathrm{tdCP}+0.166_{(0.012)} \mathrm{tdNDF}+15.74_{(1.13)} \mathrm{WSC}+34.28_{(6.39)} \mathrm{EE}$ & 0.82 & 0.048 \\
\hline $\mathrm{J}$ & (2a) & $\mathrm{ME}=-0.532_{(0.550)}+15.56_{(0.53)} \mathrm{DMd}$ & 0.83 & 0.050 \\
\hline $\mathrm{K}$ & $(2 \mathrm{~b})$ & $\mathrm{ME}=-3.520_{(0.558)}+18.53_{(0.61)} \mathrm{OMd}$ & 0.85 & 0.046 \\
\hline L & (2c) & $\mathrm{ME}=-2 \cdot 476_{(0.577)}+18 \cdot 82_{(0.67)} \mathrm{DOMD}$ & 0.83 & 0.054 \\
\hline M & $(2 d)$ & $\mathrm{ME}=-1.221_{(0.448)}+16 \cdot 51_{(0.51)} \mathrm{GEd}$ & 0.86 & 0.043 \\
\hline $\mathrm{N}$ & $(2 e)$ & $\mathrm{ME}=0.625_{(0.691)}+16 \cdot 27_{(0.57)} \mathrm{DMd}-42 \cdot 30_{(5.77)} \mathrm{N}-3.450_{(0.952)} \mathrm{ADF}$ & 0.86 & 0.064 \\
\hline $\mathrm{O}$ & (2f) & $\mathrm{ME}=-3.699_{(0.497)}+19.91_{(0.58)} \mathrm{OMd}-41.66_{(450)} \mathrm{N}$ & 0.88 & 0.051 \\
\hline $\mathrm{P}$ & $(2 \mathrm{~g})$ & $\mathrm{ME}=0.623_{(1.589)}+19.74_{(0.68)} \mathrm{DOMD}-27.75_{(7.05)} \mathrm{N}-0.18_{(0.091)} \mathrm{GE}+9.657_{(5.069)} \mathrm{EE}$ & 0.85 & 0.060 \\
\hline Q & $(2 h)$ & $\mathrm{ME}=1 \cdot 546_{(1.427)}+17 \cdot 76_{(0.50)} \mathrm{GEd}-32 \cdot 17_{(5.58)} \mathrm{N}-0.188_{(0.075)} \mathrm{GE}+2 \cdot 527_{(1.323)} \mathrm{NDF}-3.045_{(1.337)} \mathrm{ADF}$ & 0.90 & 0.050 \\
\hline $\mathrm{R}$ & (2i) & $\mathrm{ME}=1.324_{(0.504)}+0.722_{(0.030)} \mathrm{DE}$ & 0.77 & 0.051 \\
\hline $\mathrm{s}$ & (2j) & $\mathrm{ME}=0.734_{(0.430)}+0.868_{(0.030)} \mathrm{DE}-53.04_{(6.72)} \mathrm{N}-8.710_{(5.136)} \mathrm{EE}$ & 0.84 & 0.052 \\
\hline $\mathrm{T}$ & $(2 \mathrm{k})$ & $\mathrm{ME}=0.837_{(0.433)}+0.852_{(0.029)} \mathrm{DE}-59.83_{(5.34)} \mathrm{N}$ & 0.84 & 0.054 \\
\hline $\mathrm{U}$ & (2l) & $\mathrm{ME}=-1.358_{(0.755)}+0.859_{(0.035)} \mathrm{DE}+2.640_{(1.074)} \mathrm{WSC}-23.21_{(5.33)} \mathrm{EE}+3.820_{(1.013)}$ ADF & 0.81 & 0.047 \\
\hline V & $(2 \mathrm{~m})$ & $\mathrm{ME}=-2 \cdot 001_{(0.766)}+0.803_{(0.033)} \mathrm{DE}+5 \cdot 266_{(0.891)} \mathrm{WSC}+4.937_{(1.003)} \mathrm{ADF}$ & 0.79 & 0.051 \\
\hline W & $(2 n)$ & $\mathrm{ME}=4.929_{(0.658)}+0.085_{(0.011)} \mathrm{tdCP}+0.150_{(0.014)} \mathrm{tdNDF}$ & 0.57 & 0.087 \\
\hline $\mathrm{x}$ & $(20)$ & $\mathrm{ME}=1.065_{(0.786)}+0.131_{(0.015)} \mathrm{tdCP}+0.183_{(0.013)} \mathrm{tdNDF}+14.02_{(1.36)} \mathrm{WSC}$ & 0.65 & 0.078 \\
\hline $\mathrm{Y}$ & (3a) & $\mathrm{DE}: \mathrm{GE}=0.028_{(0.018)}+0.950_{(0.017)} \mathrm{DMd}$ & 0.95 & 0.029 \\
\hline Z & (3b) & $\mathrm{DE}: \mathrm{GE}=-0.143_{(0.009)}+1 \cdot 128_{(0.010)} \mathrm{OMd}$ & 0.99 & 0.010 \\
\hline$\overline{A A}$ & (3c) & $\mathrm{DE}: \mathrm{GE}=-0.082_{(0.019)}+1.146_{(0.017)} \mathrm{DOMD}$ & 0.95 & 0.029 \\
\hline$A B$ & (3d) & $\mathrm{DE}: \mathrm{GE}=0.077_{(0.021)}+0.926_{(0.018)} \mathrm{DMd}-0.112_{(0.028)} \mathrm{ADF}$ & 0.95 & 0.027 \\
\hline AC & (3e) & $\mathrm{DE}: \mathrm{GE}=-0.179_{(0.014)}+1.133_{(0.011)} \mathrm{OMd}+0.062_{(0.013)} \mathrm{NDF}$ & 0.99 & 0.009 \\
\hline$A D$ & (3f) & $\mathrm{DE}: \mathrm{GE}=-0.082_{(0.025)}+1.137_{(0.021)} \mathrm{DOMD}+0.798_{(0.167)} \mathrm{N}-0.117_{(0.046)} \mathrm{NDF}+0.181_{(0.047)} \mathrm{ADF}$ & 0.96 & 0.026 \\
\hline $\mathrm{AE}$ & (4a) & $\mathrm{ME}: \mathrm{GE}=0.016_{(0.037)}+0.793_{(0.036)} \mathrm{DMd}$ & 0.76 & 0.061 \\
\hline AF & (4b) & $\mathrm{ME}: \mathrm{GE}=-0.116_{(0.037)}+0.927_{(0.040)} \mathrm{OMd}$ & 0.76 & 0.053 \\
\hline AG & $(4 c)$ & $\mathrm{ME}: \mathrm{GE}=-0.068_{(0.038)}+0.937_{(0.044)} \mathrm{DOMD}$ & 0.75 & 0.063 \\
\hline $\mathrm{AH}$ & (4d) & $\mathrm{ME}: \mathrm{GE}=0.007_{(0.031)}+0.815_{(0.034)} \mathrm{GEd}$ & 0.77 & 0.052 \\
\hline Al & $(4 \mathrm{e})$ & $\mathrm{ME}: \mathrm{GE}=0.720_{(0.092)}+0.898_{(0.031)} \mathrm{DMd}-2.060_{(0.360)} \mathrm{N}-0.038_{(0.005)} \mathrm{GE}-0.164_{(0.055)} \mathrm{ADF}$ & 0.86 & 0.060 \\
\hline AJ & $(4 f)$ & $\mathrm{ME}: \mathrm{GE}=0.497_{(0.076)}+1.088_{(0.032)} \mathrm{OMd}-2 \cdot 116_{(0.302)} \mathrm{N}-0.038_{(0.004)} \mathrm{GE}$ & 0.88 & 0.050 \\
\hline AK & $(4 \mathrm{~g})$ & $\mathrm{ME}: \mathrm{GE}=0.739_{(0.087)}+1.106_{(0.036)} \mathrm{DOMD}-1.489_{(0.385)} \mathrm{N}-0.050_{(0.005)} \mathrm{GE}+0.497_{(0.277)} \mathrm{EE}$ & 0.85 & 0.061 \\
\hline AL & (4h) & ME:GE $=0.758_{(0.070)}+0.974_{(0.026)} \mathrm{GEd}-1.546_{(0.277)} \mathrm{N}-0.046_{(0.004)} \mathrm{GE}$ & 0.89 & 0.047 \\
\hline
\end{tabular}

$\mathrm{ME}$, grass metabolisable energy content; GE, grass gross energy content; $R^{2}$, pseudo correlation coefficient; MPE, mean prediction error; DMd, DM digestibility; OMd, organic matter digestibility; DOMD, digestible organic matter in DM; N, grass nitrogen content; EE, grass diethyl ether extract content; ADF, grass acid-detergent fibre content; WSC, grass water-soluble carbohydrate content; GEd, gross energy digestibility; NDF, grass neutral-detergent fibre content.

* Original equations are presented in Tables 2-5 and were developed by using the whole dataset.

† Units: MJ/kg DM for DE, ME and GE; kg/kg for DMd and OMd; kg/kg DM for DOMD, N, EE, ash, ADF, WSC and NDF; g/100g DM for tdCP and tdNDF; MJ/MJ for GEd. Values in subscript parentheses represent standard error. The effect of all explanatory variables was significant according to the Wald statistic (Fpr $<0.05)$, except for the effects of $E E$ in equations $P, S, A K$ and NDF in equation $Q$ which only tended to be significant $(0.05<P<0.10)$. A combination of potential random effects of cow, field, year, harvest date, fertiliser input, maturity stage and grass variety was accounted for accordingly for each predicted variable.

equations using DOMD; the latter model included N, NDF and $\mathrm{ADF}$, while the former had only ADF, as additional explanatory variable(s) according to the Wald statistic.

Using a model with GEd showed the lowest MPE, when grass ME:GE contents were predicted from $\mathrm{DMd}$, OMd, DOMD or GEd and grass chemical composition; $N$ and GE were identified as significant explanatory variables in the same model by the Wald statistic. Among the other three equations, when OMd was used as primary predictor, the Wald statistic identified the same additional explanatory variables (N, GE) as significant; MPE was found lower when compared with equations using DMd or DOMD. According to the Wald statistic, using DOMD as primary predictor showed slightly higher MPE than using DMd, and the optimum model included the combination of N, GE and EE instead of N, GE and ADF.

\section{Prediction of metabolisable energy contents of grass using digestible energy and nutrient concentrations}

According to the Wald statistic, when the prediction of grass ME content from grass DE contents and chemical composition was developed using REML analysis, the effects of grass DE, N, $\mathrm{EE}, \mathrm{WSC}$ and ADF were found significant in various models (Table 4, equations 2(i)-(m)). These equations showed similar range of MPE with prediction models for ME using nutrient digestibility and contents, although the lowest MPE observed in this set of equations (0.047, equation 2(1)) was not as low 
Table 7. Internal validation of equations developed from two-thirds of the whole dataset $(n 309)$ using the remaining one-third of the whole dataset $(n$ 155)

\begin{tabular}{|c|c|c|c|c|c|c|c|c|c|c|c|c|}
\hline \multirow[b]{2}{*}{ Equation* } & \multirow[b]{2}{*}{ Original equation } & \multirow[b]{2}{*}{ Parameters $†$} & \multirow[b]{2}{*}{ Predicted } & \multirow[b]{2}{*}{ Actual } & \multirow[b]{2}{*}{$r^{2}$} & \multirow[b]{2}{*}{ MPE } & \multirow[b]{2}{*}{ SE } & \multirow[b]{2}{*}{$R_{\mathrm{c}}$} & \multicolumn{4}{|c|}{ Predicted - Actual } \\
\hline & & & & & & & & & Mean & SD & Min & Max \\
\hline A & (1a) & $\mathrm{DE}$ & 14.46 & 14.46 & 0.85 & 0.036 & 0.301 & 0.91 & 0.007 & 0.368 & $-1 \cdot 13$ & 0.94 \\
\hline B & (1b) & $\mathrm{DE}$ & 14.50 & 14.46 & 0.89 & 0.030 & 0.303 & 0.94 & 0.044 & 0.310 & -0.58 & 1.09 \\
\hline C & (1c) & $\mathrm{DE}$ & $14 \cdot 71$ & 14.46 & 0.83 & 0.042 & 0.320 & 0.86 & 0.257 & 0.387 & -0.95 & 1.19 \\
\hline D & (1d) & DE & 14.39 & 14.46 & 0.91 & 0.028 & 0.266 & 0.95 & -0.065 & 0.280 & -1.02 & 0.59 \\
\hline $\mathrm{E}$ & (1e) & DE & 14.52 & 14.46 & 0.93 & 0.024 & 0.241 & 0.96 & 0.058 & 0.241 & -0.44 & 0.88 \\
\hline $\mathrm{F}$ & $(1 f)$ & DE & 14.48 & 14.46 & 0.95 & 0.021 & 0.206 & 0.97 & 0.022 & 0.212 & -0.53 & 0.73 \\
\hline G & (1g) & $\mathrm{DE}$ & 14.47 & 14.46 & 0.41 & 0.080 & 0.772 & 0.64 & 0.015 & 0.818 & -1.87 & 2.13 \\
\hline $\mathrm{H}$ & (1h) & $D E$ & 14.46 & 14.46 & 0.59 & 0.058 & 0.501 & 0.76 & 0.001 & 0.592 & -1.75 & 1.26 \\
\hline I & (1i) & $\mathrm{DE}$ & 14.47 & 14.46 & 0.72 & 0.048 & 0.422 & 0.84 & 0.016 & 0.490 & -1.68 & 1.11 \\
\hline $\mathrm{J}$ & (2a) & ME & 11.92 & 11.94 & 0.66 & 0.050 & 0.370 & 0.80 & -0.016 & 0.423 & -1.21 & 1.16 \\
\hline $\mathrm{K}$ & (2b) & ME & 11.81 & 11.94 & 0.74 & 0.046 & 0.375 & 0.85 & -0.127 & 0.383 & -1.09 & 1.21 \\
\hline L & (2c) & ME & $11 \cdot 85$ & 11.94 & 0.61 & 0.054 & 0.396 & 0.77 & -0.091 & 0.452 & -1.47 & 1.06 \\
\hline M & (2d) & ME & $11 \cdot 81$ & 11.94 & 0.77 & 0.043 & 0.345 & 0.86 & -0.126 & 0.355 & -1.06 & 1.08 \\
\hline $\mathrm{N}$ & $(2 e)$ & ME & 11.78 & 11.94 & 0.50 & 0.064 & 0.464 & 0.69 & -0.160 & 0.528 & -1.65 & 1.09 \\
\hline $\mathrm{O}$ & (2f) & ME & 11.84 & 11.94 & 0.67 & 0.051 & 0.397 & $0 \cdot 81$ & -0.096 & 0.423 & -1.26 & 1.20 \\
\hline $\mathrm{P}$ & (2g) & ME & 11.87 & 11.94 & 0.53 & 0.060 & 0.442 & 0.72 & -0.068 & 0.508 & -1.56 & 1.23 \\
\hline Q & $(2 h)$ & ME & $11 \cdot 86$ & 11.94 & 0.67 & 0.050 & 0.401 & 0.82 & -0.075 & 0.424 & -1.46 & 1.20 \\
\hline $\mathrm{R}$ & (2i) & ME & $11 \cdot 76$ & 11.94 & 0.68 & 0.051 & 0.376 & 0.80 & -0.177 & 0.411 & -1.40 & 1.12 \\
\hline $\mathrm{S}$ & (2j) & ME & 11.84 & 11.94 & 0.63 & 0.052 & 0.371 & 0.78 & -0.100 & 0.436 & -1.40 & 0.92 \\
\hline $\mathrm{T}$ & (2k) & ME & $11 \cdot 82$ & 11.94 & 0.61 & 0.054 & 0.386 & 0.76 & -0.122 & 0.449 & -1.49 & 0.93 \\
\hline U & (2l) & ME & 11.82 & 11.94 & 0.70 & 0.047 & 0.326 & 0.81 & -0.121 & 0.392 & -1.26 & 1.02 \\
\hline V & $(2 \mathrm{~m})$ & ME & 11.77 & 11.94 & 0.67 & 0.051 & 0.345 & 0.78 & -0.169 & 0.412 & -1.39 & 0.91 \\
\hline W & $(2 n)$ & ME & 11.88 & 11.94 & 0.18 & 0.087 & 0.595 & 0.42 & -0.061 & 0.737 & -1.95 & 2.02 \\
\hline$x$ & (2o) & ME & $12 \cdot 07$ & 11.94 & 0.23 & 0.078 & 0.455 & 0.45 & 0.127 & 0.652 & -1.67 & 1.71 \\
\hline Y & (3a) & DE:GE & 0.79 & 0.79 & 0.86 & 0.029 & 0.014 & 0.92 & -0.001 & 0.016 & -0.06 & 0.03 \\
\hline Z & (3b) & DE:GE & 0.79 & 0.79 & 0.99 & 0.010 & 0.005 & 0.99 & 0.001 & 0.005 & -0.02 & 0.02 \\
\hline AA & (3c) & DE:GE & 0.79 & 0.79 & 0.86 & 0.029 & 0.015 & 0.92 & 0.001 & 0.016 & -0.03 & 0.04 \\
\hline$A B$ & (3d) & DE:GE & 0.79 & 0.79 & 0.88 & 0.027 & 0.014 & 0.94 & -0.001 & 0.015 & -0.06 & 0.03 \\
\hline AC & (3e) & DE:GE & 0.79 & 0.79 & 0.99 & 0.009 & 0.005 & 0.99 & 0.000 & 0.005 & -0.02 & 0.02 \\
\hline$A D$ & (3f) & DE:GE & 0.79 & 0.79 & 0.89 & 0.026 & 0.013 & 0.94 & 0.001 & 0.015 & -0.03 & 0.04 \\
\hline$A E$ & (4a) & ME:GE & 0.65 & 0.65 & 0.49 & 0.061 & 0.023 & 0.68 & -0.001 & 0.028 & -0.08 & 0.08 \\
\hline $\mathrm{AF}$ & (4b) & ME:GE & 0.65 & 0.65 & 0.62 & 0.053 & 0.023 & 0.78 & -0.001 & 0.025 & -0.07 & 0.07 \\
\hline$A G$ & (4c) & ME:GE & 0.65 & 0.65 & 0.46 & 0.063 & 0.023 & 0.65 & -0.007 & 0.029 & -0.09 & 0.07 \\
\hline $\mathrm{AH}$ & (4d) & ME:GE & 0.65 & 0.65 & 0.63 & 0.052 & 0.021 & 0.79 & -0.002 & 0.024 & -0.07 & 0.07 \\
\hline $\mathrm{Al}$ & $(4 e)$ & ME:GE & 0.65 & 0.65 & 0.53 & 0.060 & 0.025 & 0.72 & 0.001 & 0.028 & -0.08 & 0.07 \\
\hline AJ & $(4 f)$ & ME:GE & 0.65 & 0.65 & 0.69 & 0.050 & 0.022 & 0.83 & 0.002 & 0.023 & -0.06 & 0.08 \\
\hline AK & $(4 g)$ & ME:GE & 0.65 & 0.65 & 0.52 & 0.061 & 0.025 & 0.72 & -0.005 & 0.028 & -0.09 & 0.07 \\
\hline $\mathrm{AL}$ & (4h) & ME:GE & 0.65 & 0.65 & 0.72 & 0.047 & 0.021 & 0.85 & -0.002 & 0.022 & -0.07 & 0.07 \\
\hline
\end{tabular}

$r^{2}$, correlation between predicted and actual values; MPE, mean prediction error; $R_{\mathrm{c}}$, Lin's concordance correlation coefficient; Min, minimum value observed; Max, maximum value observed; DE, grass digestible energy content; ME, grass metabolisable energy content; GE, grass gross energy content.

*Equations are presented in Table 6.

†Units: MJ/kg DM for DE, ME and GE.

as the lowest observed when nutrient digestibility was used (0.043, equation 2(d)). When using the present set of data, it was observed that the addition of grass chemical composition parameters to prediction models for ME from DE improved MPE, but only when grass $\mathrm{N}$ contents were not among the explanatory variables, although the latter was also identified as a significant predictor according to the Wald statistic.

When using all available chemical composition parameters in the analyses in a model with DE as the primary predictor, the Wald statistic identified $\mathrm{N}$ and $\mathrm{EE}$ contents of grass as additional significant explanatory variables. However, this model showed slightly increased MPE, when compared to the model using DE as sole predictor and it also showed an increased MPE when further excluding EE from the multivariate model (thus leaving only DE and $\mathrm{N}$ as predictors). When using all available chemical composition parameters (excepting $\mathrm{N}$ ) in the analyses, in a model with DE as the primary predictor, the Wald statistic identified WSC, EE and ADF contents of grass as additional significant explanatory variables. This model showed the lowest MPE among all models that included DE as primary predictor. However, it also showed an MPE value similar to that of the model using DE as the sole predictor, by further excluding EE from the multivariate model (thus leaving only DE, WSC and ADF as predictors).

\section{Prediction of digestible energy and metabolisable energy contents of grass using total digestible nutrients and nutrient concentrations}

When DE and ME concentrations of grass were predicted from tdCP, tdNDF and WSC and EE contents of grass, using REML analysis (Table 5, equations 1(g)-(i), 2(n), 2(o)), the effect of all explanatory variables was significant, except for the effect 
Table 8. Validation of equations previously published for the prediction of metabolisable energy (ME) from grass chemical composition, digestible energy (DE) and digestible organic matter in DM (DOMD), using one-third of the whole dataset $(n$ 155)

\begin{tabular}{|c|c|c|c|c|c|c|c|c|c|c|c|}
\hline \multirow[b]{2}{*}{ Equation } & \multirow[b]{2}{*}{ Equations for the prediction of $\mathrm{ME}^{\star}$} & \multirow[b]{2}{*}{ Predicted } & \multirow[b]{2}{*}{ Actual } & \multirow[b]{2}{*}{$r^{2}$} & \multirow[b]{2}{*}{ MPE } & \multirow[b]{2}{*}{ SE } & \multirow[b]{2}{*}{$R_{\mathrm{c}}$} & \multicolumn{4}{|c|}{ Predicted - Actual } \\
\hline & & & & & & & & Mean & SD & Min & $\operatorname{Max}$ \\
\hline AM & $\mathrm{ME}=9 \cdot 1+15 \cdot 3 \mathrm{CP}$ & $11 \cdot 24$ & 11.94 & 0.16 & 0.106 & 0.593 & 0.26 & -0.700 & 0.749 & $-2 \cdot 57$ & 1.21 \\
\hline AN & $\mathrm{ME}=18.9-13.3 \mathrm{NDF}$ & $12 \cdot 20$ & 11.94 & 0.18 & 0.083 & 0.452 & 0.36 & 0.257 & 0.680 & $-1 \cdot 87$ & 2.06 \\
\hline AO & $\mathrm{ME}=16 \cdot 2-17 \cdot 0 \mathrm{ADF}$ & 11.65 & 11.94 & 0.12 & 0.095 & 0.598 & 0.31 & -0.291 & 0.776 & -2.93 & 1.62 \\
\hline AP & $\mathrm{ME}=0.815 \mathrm{DE}$ & 11.78 & 11.94 & 0.68 & 0.053 & 0.424 & 0.81 & -0.156 & 0.434 & -1.34 & 1.26 \\
\hline$A Q$ & $\mathrm{ME}=4.184 \times(1.01 \times((\mathrm{DE} / 4.184)-0.45)))$ & $12 \cdot 72$ & 11.94 & 0.68 & 0.090 & 0.526 & 0.55 & 0.780 & 0.526 & -0.32 & 2.43 \\
\hline AR & $\mathrm{ME}=3.47+10.2 \mathrm{DOMD}+3.0 \mathrm{CP}$ & 11.65 & 11.94 & 0.62 & 0.060 & 0.249 & 0.60 & -0.287 & 0.469 & -1.91 & 0.86 \\
\hline AS & $\mathrm{ME}=5.85+8.7 \mathrm{DOMD}+4.2 \mathrm{CP}$ & $12 \cdot 57$ & 11.94 & 0.63 & 0.080 & 0.186 & 0.35 & 0.626 & 0.511 & $-1 \cdot 14$ & 1.79 \\
\hline AT & $\mathrm{ME}=0.37+14.2 \mathrm{DOMD}+7.7 \mathrm{CP}$ & $12 \cdot 25$ & 11.94 & 0.58 & 0.063 & 0.433 & 0.69 & 0.315 & 0.481 & -1.02 & 1.98 \\
\hline AU & $\mathrm{ME}=-0.232+13.9 \mathrm{DOMD}+10.05 \mathrm{CP}$ & 11.75 & 11.94 & 0.54 & 0.064 & 0.499 & 0.71 & -0.187 & 0.529 & -1.58 & 1.70 \\
\hline AV & $\mathrm{ME}=16 \mathrm{DOMD}$ & $12 \cdot 18$ & 11.94 & 0.61 & 0.056 & 0.336 & 0.70 & 0.238 & 0.447 & $-1 \cdot 26$ & 1.34 \\
\hline
\end{tabular}

$r^{2}$, correlation between predicted and actual values; MPE, mean prediction error; $R_{\mathrm{c}}$, Lin's concordance correlation coefficient; Min, minimum value observed; Max, maximum value observed; CP, grass crude protein content; NDF, grass neutral-detergent fibre content; ADF, grass acid-detergent fibre content.

* Equations AM, AN, AO, AR, AS, AT were published by Givens et al. ${ }^{(20)}$, equations AP and AU by Terry et al. ${ }^{(21)}$, equation AQ by National Research Council ${ }^{(5)}$ and equation AV from Agricultural and Food Research Council ${ }^{(6)}$. Units: MJ/kg DM for ME and DE; kg/kg DM for CP, NDF, ADF and DOMD. In equation AQ, 1 Mcal = 4.184 MJ was used when revising the original model to represent $\mathrm{MJ}^{(6)}$. In equations $A R$ and $A S$, DOMD was measured by NDF-cellulase and pepsin-cellulase, respectively, and in equations AT and AU, DOMD was measured by rumen fluid.

of EE in the prediction of ME. Predictions of DE and ME from this set of variables showed the highest MPE compared to those of all other models developed in the present study. For the prediction of DE and ME, stepwise addition of WSC and EE (only in the case of DE) showed decreased MPE, in a model which already includes tdCP and tdNDF as explanatory variables.

\section{Internal validation of prediction equations}

Thirty-eight new predictions, one for each equation developed in the present study by using the whole dataset, were developed from two-thirds of data by using the same random and fixed model and they are presented in Table 6 (equations $\mathrm{A}-\mathrm{AL}$ ). These new equations were validated using the remaining one-third of the dataset, and the outcome is presented in Table 7 .

Mean predicted values were very close to the actual data for all the predicted energy concentration and ratio parameters. MPE (1) were lower for the predictions of DE:GE (0.0090.029 , average $=0.022$ ), (2) showed intermediate values for the predictions of $\mathrm{DE}(0 \cdot 021-0 \cdot 080$, average $=0 \cdot 041)$, and (3) were higher for the predictions of ME (0.043-0.087, average $=0.056)$ and ME:GE (0.047-0.063, average $=0.056)$.
Mean differences between the predicted and actual values represented less than $1 \cdot 8,3 \cdot 1,0 \cdot 2$, and $0.9 \%$ for DE, ME, DE:GE and ME:GE, respectively, with some models showing a difference as low as $0.01,0.13,0.03$ and $0.14 \%$ of the actual values, respectively. Similarly, the proportions of standard errors in relation to the actual values for DE, ME, DE:GE and ME:GE were less than 5.4, 5.0, 1.9 and 3.9\%, respectively, with equations showing proportions as low as $1 \cdot 4,2 \cdot 7,0 \cdot 7$ and $3 \cdot 2 \%$ of the actual values, respectively.

Equations previously published for the prediction of $\mathrm{ME}$ concentrations $^{(5,6,20,21)}$ from DE or nutrient digestibility and contents were also validated against the same one-third of dataset, and the results are presented in Table 8 (equations $\mathrm{AM}-\mathrm{AV}$ ). The MPE of these equations were found to be higher, when compared with those of the equations developed in the present study. The use of DE as the sole predictor, as shown by Terry et al. ${ }^{(21)}$, showed lower MPE when compared with that of DOMD as the sole predictor ${ }^{(6)}$, or in conjunction with crude protein content of grass ${ }^{(20,21)}$.

In order to assess agreement between predicted and actual values in the equations developed in the present or previously published ${ }^{(5,6,20,21)}$ studies, an agreement analysis using Lin's concordance correlation coefficient was performed, and the results
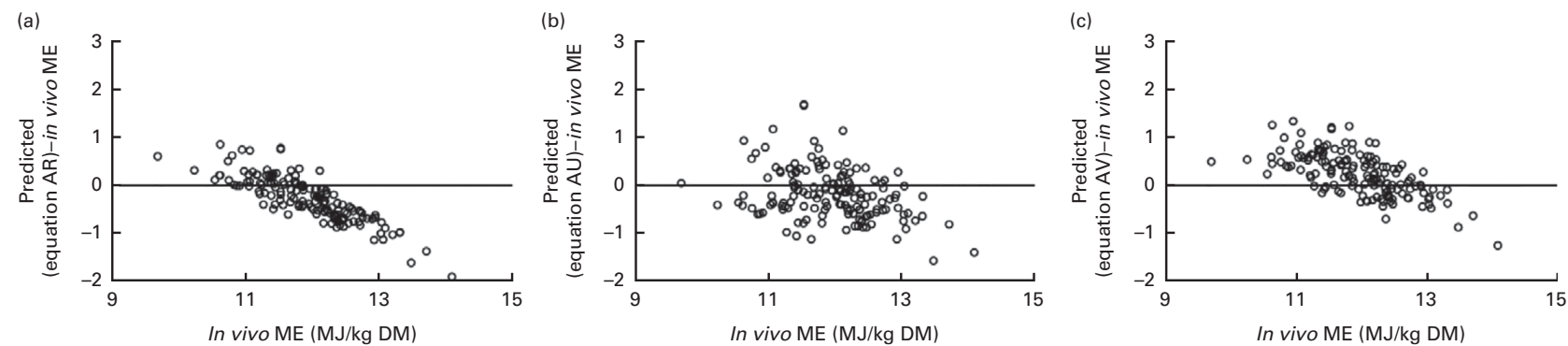

Fig. 1. Bland-Altman plots showing the agreement between in vivo measured metabolisable energy (ME) and residual (predicted minus actual) ME, with ME being predicted from equations published in other studies ((a) Givens et al. ${ }^{(20)}$; (b) Terry et al. ${ }^{(21)}$; (c) Agricultural and Food Research Council $\left.{ }^{(6)}\right)$ by using digestible organic matter in DM and crude protein as predictors (a and b) or digestible organic matter in DM as the sole predictor (c). (a) $R_{\mathrm{c}} 0.603$ (95\% $\mathrm{Cl} 0.529$, 0.668), (b) $R_{\mathrm{c}} 0.709(95 \% \mathrm{Cl} 0.624,0.778)$ and (c) $R_{\mathrm{c}} 0.703(95 \% \mathrm{Cl} 0.626,0.766)$, where $R_{\mathrm{c}}$ is Lin's concordance correlation coefficient. DM represents DM content of fresh grass. Prediction equations are shown in Table 8 (equations AR, AU and AV). 
(a)

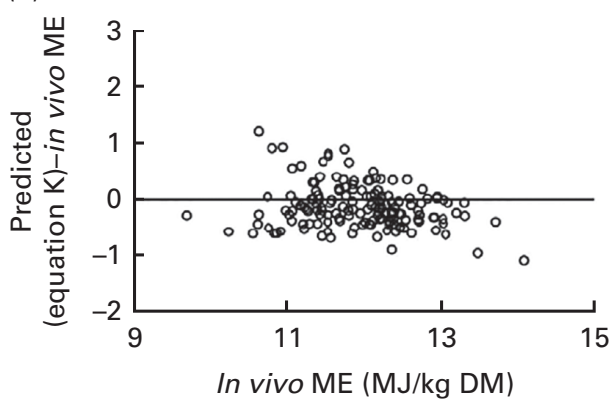

(c)

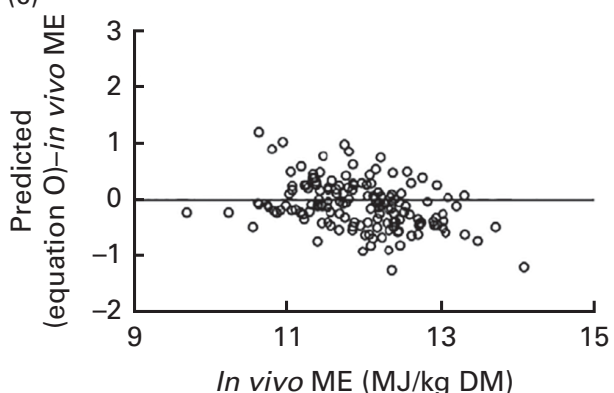

(b)

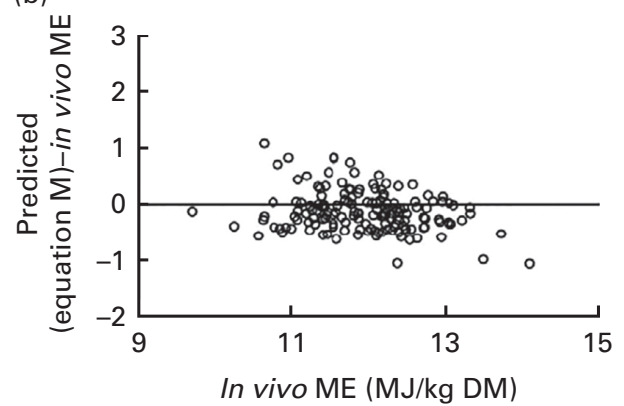

(d)

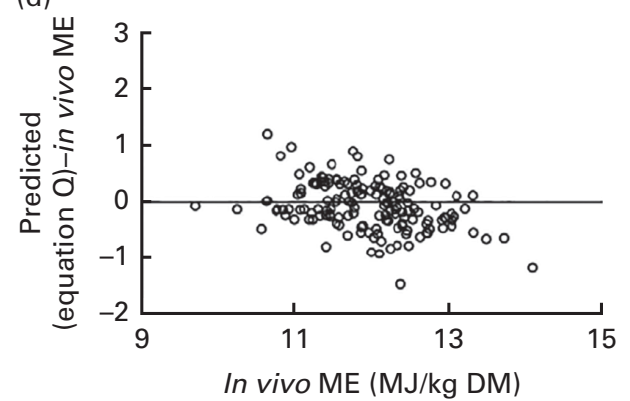

Fig. 2. Bland-Altman plots showing the agreement between in vivo measured metabolisable energy (ME) and residual (predicted minus actual) ME, with ME being predicted from equations developed in the present study using two-thirds of the whole dataset, and by using nutrient digestibility and grass chemical composition parameters as predictors (predictors used: (a) organic matter digestibility; (b) gross energy digestibility; (c) organic matter digestibility and grass nitrogen content; and (d) gross energy digestibility and grass contents of nitrogen, gross energy, neutral-detergent fibre and acid-detergent fibre). (a) $R_{\mathrm{c}} 0.848$ (95\% $\mathrm{Cl}$ $0.798,0.887$ ), (b) $R_{\mathrm{c}} 0.864$ (95\% Cl $\left.0.819,0.899\right)$, (c) $R_{\mathrm{c}} 0.813\left(95 \% \mathrm{Cl} 0.752,0.760\right.$ ) and (d) $R_{\mathrm{c}} 0.817$ (95\% Cl $\left.0.757,0.763\right)$, where $R_{\mathrm{c}}$ is Lin's concordance correlation coefficient. DM represents DM content of fresh grass. Prediction equations are shown in Table 6 (equations K, M, O, Q).

are presented in Tables 7 and 8 respectively. Bland-Altman plots were generated to graphically represent the agreement between in vivo measured $\mathrm{ME}$ values and the difference between predicted and actual values for the equations: (1) that they showed the lowest MPE among the ones using nutrient digestibility and chemical composition of grass (Figs. 1 and 2) or using DE and chemical composition of grass (Fig. 3), and (2) that they are being used in the existing energy feeding systems in the $\mathrm{UK}^{(6)}$ (Fig. 1) and the US ${ }^{(5)}$ (Fig. 2). Lin's concordance correlation coefficients and $95 \% \mathrm{CI}$ are also shown in the same graphs, and they all recorded some agreement between predicted and actual values. These plots showed an under-prediction of ME when actual values were over $11 \cdot 8-12 \cdot 3 \mathrm{MJ} / \mathrm{kg}$ DM. The scatter of differences between predicted and actual values was smaller for the equations developed in the present analysis, by using nutrient contents and digestibility parameters as predictors, when compared with previous ${ }^{(20,21)}$ studies across the range of the in vivo measured ME values. When DE was used to predict ME, the scatter was only slightly improved in the equations developed in the present study when compared to the scatter of those published by Terry et al. ${ }^{(21)}$; also it indicated a lower average difference between predicted and actual values of the former. However, the recommended equation from the $\mathrm{NRC}^{(5)}$ over-predicted $\mathrm{ME}$ throughout the range of in vivo $\mathrm{ME}$ investigated.

\section{Discussion}

Compared with other works that developed prediction equations for grass ME using nutrient digestibility and laboratory measurements, the present study differed in some exclusive features. Firstly, the grass fed varied considerably in nutrient composition, as a result of growing in highly variant swards in terms of harvest date (primary growth, first regrowth, second regrowth), maturity (3 to 9 weeks), fertiliser input $(8-70 \mathrm{~kg}$ $\mathrm{N} / \mathrm{ha}$ ) and grass variety (six different seed mixtures). Secondly, the number of samples ( $n$ 464, as a result of 3-d averaged 1392 records) was over 2.5 times higher than that in similar studies ${ }^{(20)}$, with records being evenly collected over the different treatments, which were considered the main sources of the variation in grass quality. Thirdly, energy losses in methane production were systematically measured in calorimetric chambers in the first year and methane energy data were calculated from equations developed from part of the same dataset ${ }^{(13)}$ used to develop the prediction equations in the present study, instead of using published equations from independent datasets. Last but not least, the present study was performed with cattle fed fresh grass to meet maintenance energy requirements, instead of sheep or cows fed at higher feeding levels; the latter are the most commonly used ones in ruminant metabolism research for the development of energy prediction equations and values of feeding tables ${ }^{(5,6,8,20)}$. Compared with sheep, the digestibility in cattle is lower when offered diets that have a DMd above $660 \mathrm{~g} / \mathrm{kg}$, whereas the reverse is true for diets with a DMd lower than $660 \mathrm{~g} / \mathrm{kg}$ and this may underestimate energy values for forages in the latter case ${ }^{(22)}$. Similar findings were reported by Yan et al. ${ }^{(23)}$, based on direct comparisons of sheep and cattle fed silage-based diets, but little difference was observed when ensiled forage was offered at maintenance level. 
(a)

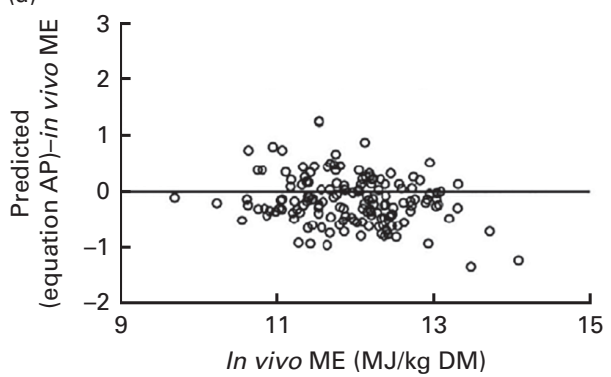

(c)

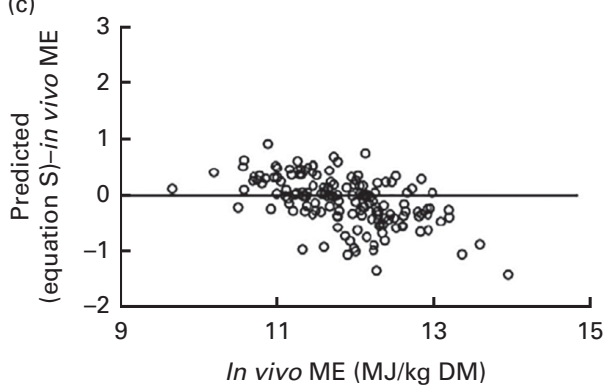

(b)

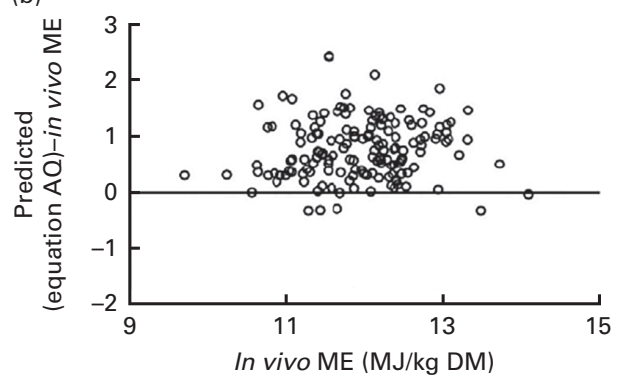

(d)

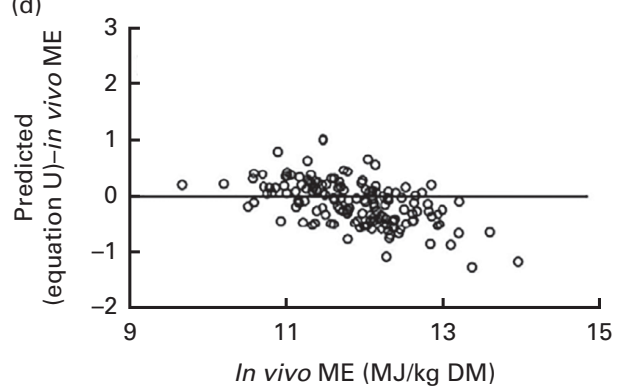

Fig. 3. Bland-Altman plots showing the agreement between in vivo measured metabolisable energy (ME) and residual (predicted minus actual) ME, with ME being predicted from equations previously published ((a) Terry et al. ${ }^{(21)}$; (b) National Research Council ${ }^{(5)}$ ) or developed in the present study using two-thirds of the whole dataset ( $c$ and $d$ ), and by using digestible energy and grass chemical composition parameters as predictors (predictors used: (a) and (b) digestible energy; (c) digestible energy and grass contents of nitrogen and ether extract; (d) digestible energy and grass contents of water-soluble carbohydrates, ether extract and acid-detergent fibre). (a) $R_{\mathrm{c}} 0.806$ (95\% Cl $\left.0.745,0.854\right)$, (b) $R_{\mathrm{c}} 0.554$ (95\% Cl $\left.0.477,0.622\right),(\mathrm{c}) R_{\mathrm{c}} 0.778(95 \% \mathrm{Cl} 0.710,0.831)$ and (d) $R_{\mathrm{c}} 0.810(95 \% \mathrm{Cl}$ $0.752,0.855), R_{c}$ represents Lin's concordance correlation coefficient. DM represents DM content of fresh grass. Prediction equations are shown in Table 6 (equations $\mathrm{S}$ and $\mathrm{U}$ ) and Table 8 (equations $\mathrm{AP}$ and $\mathrm{AQ}$ ).

The equations developed in the present study may be used in a wide range of pasture-based systems, where pure ryegrass swards are used, because they have been developed with animals fed fresh-cut grass of a highly diverse quality. These equations may not be efficient in predicting energy concentrations of swards of different botanical composition, because other forage plants were not assessed. Also, small differences regarding energy expenditure for foraging and the number and duration of meals may occur between zero-grazing and grazing in situ animals, which would probably slightly influence energy utilisation. These differences are difficult to be taken into consideration in metabolism experiments, because an accurate total $24 \mathrm{~h}$ collection of faeces and urine at pasture is not possible in practice. However, existing feeding systems recommend various correction factors for grazing cattle given that all equations used in animal rationing have been developed with housed livestock.

\section{Prediction of digestible energy and metabolisable energy contents of grass using digestibility of nutrients as sole predictor}

The positive relation between DMd, OMd and DOMD with DE and ME contents of grass was not surprising, because higher digestibility of these nutrient groups would decrease energy losses in faeces ${ }^{(24)}$. The most accurate prediction of ME in the present study was achieved when GEd was used as the sole predictor, and this may be due to the fact that energy losses in faeces, which define GEd, represented over 0.605 of total energy losses. An improved precision of the prediction of ME by using predictors which account for the proportional energy loss in faeces has previously been recommended by Givens et $a l .{ }^{(20)}$ as well. However, GEd is not as extensively available as DMd, OMd or DOMD in practice, and equations based on the last three of these nutrient digestibility parameters may be necessary under commercial conditions. Among these three potential predictors, OMd was the most accurate for predicting DE and ME, based on the lower MPE observed in the equations using OMd as sole predictor, when compared with equations using DMd or DOMD. This may be explained by the inclusion of ash, which contains no energy, but is present in grass DM content, which influences DMd and DOMD values. However, MPE values were also relatively low when using either DMd or DOMD and, practically, these explanatory variables may be used for the prediction of ME content of fresh grass when details of GEd or OMd are not available. The importance of using digestibility parameters for the prediction of $\mathrm{DE}$ and ME is noteworthy because equations based only on laboratory measurements of grass derived relatively higher MPE in a previous study, either using equations developed from the same data as in the present study (MPE $=0.091$ ) or those published by other authors $(\mathrm{MPE}=0.094)^{(12)}$; the same was observed to be the case in the present work when previously published equations $^{(20)}$ were validated.

It is however notable that using NDFd as sole predictor also showed an MPE similar to that of using DMd (0.050; online Supplementary Fig. S1). In a recent study in Ireland, NDF, ADF and CP contents in four commonly used varieties of Lolium perenne L. were measured at an average of 0.386 , 0.247 and 0.233 of $\mathrm{DM}$ respectively during the vegetative growth stage ${ }^{(25)}$. In the present study, the respective contents 
were found to be $0 \cdot 503,0 \cdot 267$ and $0 \cdot 141$ of $\mathrm{DM}$, because a wider range of grass quality was investigated. Therefore, NDF accounts for a larger proportion of the DM contents than ADF or $\mathrm{N}$, and the regression of NDFd digestibility against ME contents of grass tended to be similar to that of $\mathrm{DMd}$.

\section{Prediction of digestible energy and metabolisable energy contents of grass using nutrients' concentrations and digestibility}

The addition of nutrient contents of grass as predictors in the equations based on nutrient digestibility parameters improved MPE, and seemed necessary in order to optimise the prediction of DE contents of grass in practice. N, GE, EE and ADF of grass were identified as significant predictors by the Wald statistic in various equations. Interestingly, when chemical composition of grass is not available, the use of equations based on $\mathrm{OMd}$ may be recommended. However, when nutrient contents of grass are known, an equation using DOMD as primary predictor would show lower MPE and require less additional explanatory variables (only $\mathrm{N}$ and $\mathrm{EE}$ ) than an equation using OMd (which requires N, EE, WSC and ash). Therefore, decisions on the optimum models to predict DE in practice should be made based on what analyses are available to the researchers, nutritionists, analysts or producers.

In contrast with DE contents of grass, the MPE for the prediction of ME was slightly increased by adding nutrient content parameters as predictors to equations already using nutrient digestibility parameters. However, the average difference between predicted and actual values was reduced by 40 and $24 \%$ when chemical composition of grass parameters were used as additional predictors in equations using GEd and OMd respectively, followed by a respective increase in the explained variation. This may imply that although the addition of chemical composition of grass parameters may be preferable in order to account for the type of nutrient within the digestible organic matter that provides the energy, the less complicated equations developed in the present study by using OMd or GEd as sole predictor may also offer a reliable option for the prediction of ME of grass for grazing cattle.

Higher $\mathrm{N}$ contents in feeds have previously been associated with an increase in DE and ME concentrations ${ }^{(22)}$. Positive and negative correlations of $\mathrm{N}$ and $\mathrm{ADF}$ contents of grass, respectively, with energy contents of grass were also seen in the present dataset as previously reported ${ }^{(12)}$. Notably, N content of grass was identified by the Wald statistic as a significant explanatory variable in all prediction equations, thus emphasising its importance to the energy evaluation of fresh-cut grass in order to account for the possible losses associated with its metabolism and excretion in grazing cattle ${ }^{(9)}$. The negative intercepts in the prediction equations of grass $\mathrm{N}$ content were not associated to a negative relationship with ME, because the correlation coefficient of their univariate linear regression was positive ${ }^{(12)}$. This finding was more likely a result of confounding effects when digestibility parameters were used as primary predictors in the same equation. Also, in the the present study, animals were fed iso-energetic diets regardless of $\mathrm{N}$ concentrations in grass. This may have led to
$\mathrm{N}$ underfeeding or overfeeding in cases of poor quality or high-protein grass respectively. Feeding $\mathrm{N}$ below requirements might interact with the other explanatory variables in the same equations, because it is associated with reductions of $\mathrm{DMd}$ and $\mathrm{OMd}^{(26)}$. Likewise, cases of $\mathrm{N}$ overfeeding might increase energy losses for the hepatic synthesis of urea (which may account for up to $4 \%$ of ME), excretion to kidneys, $\mathrm{N}$ turnover and ammonia removal process ${ }^{(9,24)}$. The latter may in particular occur in the absence of concentrate feeds, because inadequate readily available energy in rumen may decrease utilisation of high amounts of rapidly degradable $\mathrm{N}$ by rumen microbial population ${ }^{(27)}$. This would not affect DE evaluation (a positive intercept with grass $\mathrm{N}$ contents was found), but would reduce ME contents because the excess of $\mathrm{N}$ intake is excreted in urine rather than in faeces ${ }^{(11)}$.

According to the Wald statistic, the finding of the present study that EE contents of grass strongly affected energy contents is in line with Givens et $a l .{ }^{(20)}$, with slopes being higher than those for other nutrients (except $\mathrm{N}$ ), indicating a higher effect on a per weight basis; the latter possibly shows limited practical importance due to the low concentrations and variation of EE in grass compared with those of other nutrients.

The other main explanatory variables were GE, NDF and ADF, as identified by the Wald statistic during fixed model development for the predictions of $\mathrm{DE}$ and ME. Content of GE of grass was used by Givens et $a l .^{(20)}$ while fibre contents are used in the French and Australian energy systems in the forms of crude fibre and ADF or modified ADF respectively ${ }^{(8,22)}$. NDF and ADF contents of grass showed a negative relation with $\mathrm{DE}, \mathrm{ME}$ and ME:GE concentrations, possibly as a result of increased energy excretion in faeces with higher ADF intake ${ }^{(20)}$.

The ratio of ME:GE represents the efficiency of energy utilisation in the animal, and its practical implications may directly influence the $\mathrm{UK}^{(6)}$, the French ${ }^{(8)}$, the Australian ${ }^{(22)}$ and the Dutch $^{(28)}$ systems. In these energy evaluation systems, the ratio ME:GE is used to predict the partial efficiencies of milk and meat production and, in turn, the net energy value of feeds, from prediction equations using $\mathrm{ME}$ as the primary explanatory variable. Equations developed in the present study showed that the prediction error may be lowest when grass $\mathrm{N}$ and GE contents are used in conjunction with GEd (optimum model) or OMd (to be recommended when GEd is not available). When details of GEd or OMd are not known, DMd or DOMD may be used as primary predictors but this would reduce prediction accuracy and would also require the addition of $\mathrm{ADF}$ or $\mathrm{EE}$, respectively, in the models.

Bland-Altman plots investigating the agreement between predicted values, from equations using nutrient contents and digestibility parameters as predictors, and the difference between predicted and invivo measured ME, showed that predicted values were generally lower than actual values when ME contents of grass were relatively high. This pattern appeared in the predictions based on the equation of Givens et al. ${ }^{(20)}$ for ME values over $11.8 \mathrm{MJ} / \mathrm{kg} \mathrm{DM}$, while in the equation of Terry et $a l^{(21)}$, this appeared at slightly higher values (over $12.8 \mathrm{MJ} / \mathrm{kg}$ DM). Interestingly, the equations currently used in the UK feeding system $^{(6)}$ over-predicted ME when in vivo measured ME was 
lower than $11.3 \mathrm{MJ} / \mathrm{kg} \mathrm{DM}$, but under-predicted $\mathrm{ME}$ when in vivo measured ME was over $12 \cdot 8 \mathrm{MJ} / \mathrm{kg}$ DM. This may be a result of the fact that the existing equation does not take into consideration the nutrient composition of DOMD. Poor quality pasture (with less N and EE and more WSC and fibre) may contain less ME per kg of DOMD than high quality pasture (with more $\mathrm{N}$ and $\mathrm{EE}$ and less fibre), because energy content of $\mathrm{N}$ and $\mathrm{EE}$ is higher, per weight, than that of WSC and fibre. Therefore, by multiplying solely DOMD with a single factor to predict ME may over-predict $\mathrm{ME}$ in poor quality grass, and under-predict ME in good quality grass; the latter highlights the necessity of including chemical composition of grass parameters in the predictions of ME of grass for grazing cattle. Equations developed in the present study also generally under-predicted ME when actual values were higher than $12.8 \mathrm{MJ} / \mathrm{kg}$ DM. However, the difference between predicted and actual values was smaller, thus offering support to the observation that the new equations may decrease the possible error in prediction within this range. This was also found applicable for the whole range of ME values, as implied by the lower MPE of the equations developed in the present study.

The findings of the present study are in accordance with previous reports and recommendations that the feeding value of grass can be more accurately predicted when parameters of nutrient content and digestibility are used in combination $^{(22,24)}$. The same has also been recommended for the prediction of $\mathrm{ME}$ contents in feeds in experiments with silage-based $\operatorname{diets}^{(7)}$.

\section{Prediction of metabolisable energy contents of grass using digestible energy and nutrient concentrations}

Similar to $\mathrm{NRC}^{(5)}$ recommendations, predictions of ME contents using DE as sole predictor were developed in the present study while regressions using $\mathrm{DE}$ in conjunction with chemical contents of grass were also investigated. Although using DE as the sole predictor showed relatively low MPE, the inclusion of WSC, EE and ADF contents of grass as predictors may be recommended for further improvement of prediction accuracy in practice. However, if $\mathrm{EE}$ is not available in practice, adding just WSC and ADF as predictors may not improve prediction accuracy, but, in the present study, it still reduced standard error and the difference between predicted and actual values by 13 and $32 \%$ respectively, explaining the variation further when compared with the equation using DE as the sole predictor. The positive association between WSC, EE and ADF with ME can be explained by (1) the fact that these nutrients would be the main source of energy for $\mathrm{N}$ utilisation by rumen microbes and (2) the negative relation of grass $\mathrm{N}$ with WSC and fibre contents ${ }^{(27,29)}$; these two features would decrease energy losses related to excess $\mathrm{N}$ metabolism and excretion ${ }^{(9)}$.

The significant effect of grass $\mathrm{N}$ on the prediction of ME may be explained by the fact that the difference between DE and $\mathrm{ME}$ is highly dependent on energy excretion in urine, and consequently on $\mathrm{N}$ intakes and outputs ${ }^{(24)}$. Although this was observed in the present study and the Wald statistic too identified grass $\mathrm{N}$ content as significant predictor of $\mathrm{ME}$ when DE was used as primary predictor, the addition of $\mathrm{N}$ and EE increased MPE when compared with the equation using DE as the sole predictor; but it also explained more variation and decreased the average difference between predicted and actual ME by $44 \%$. Therefore, using grass $\mathrm{N}$ content as an additional predictor may be recommended when WSC and ADF are not available in practice.

Bland-Altman plots were drawn to assess the agreement between predicted values, from equations using DE and nutrient contents as predictors, and the difference between predicted and in vivo measured ME; they showed, similar to equations using nutrient contents and digestibility, that ME was underpredicted for ME values over $12.8 \mathrm{MJ} / \mathrm{kg} \mathrm{DM}$ in all equations, either in previously published studies ${ }^{(21)}$ or developed in the present study. However, the smaller MPE of the equation developed in the present study implied that using (1) the updated equations when DE is the sole predictor and (2) WSC, $\mathrm{EE}$ and $\mathrm{ADF}$ as additional predictors when available in practice, may improve ME prediction accuracy. Interestingly, the current equation presented by $\mathrm{NRC}^{(5)}$ showed an over-prediction of grass ME contents throughout the whole ME range investigated in the present study, implying a possible under-supply of ME by using NRC's equation for grazing cattle.

\section{Prediction of digestible energy and metabolisable energy contents of grass using total digestible nutrients and nutrient concentrations}

For the prediction of $\mathrm{DE}$ and $\mathrm{ME}$ contents of grass, $\mathrm{NRC}^{(5)}$ recommends equations using chemical composition of grass as explanatory variables (NDF, crude protein, EE, ash, and lignin), in conjunction with truly digestible nutrients (non structural fibre carbohydrates, crude protein and NDF). A couple of limitations may occur in their use for pasturebased systems, because these equations were developed with animals fed on conserved forage and concentrates at three times maintenance level. Similar explanatory variables were used to predict ME contents in forages in the Dutch system $^{(28)}$, with non-lactating cows fed at 0.5-1.7 times maintenance level. Based on the principles of these two systems, and in an attempt to simplify the existing relations to meet the UK routine laboratory analyses, equations in the present study were developed by using tdCP and tdNDF as primary predictors, by also adding contents of EE and WSC of grass. Indeed, these parameters showed a significant effect on the prediction of DE and ME, and MPE was decreased when EE and WSC were added in the equations, although the effect of $\mathrm{EE}$ contents on the prediction of ME was not significant according to the Wald statistic. However, NDFd was used to calculate tdNDF; MPE was relatively low (0.050; online Supplementary Fig. S1), when NDFd was used as the sole predictor in cases where details of GEd, $\mathrm{OMd}$, DMd or DOMD were not used. Therefore, using NDFd seems to be an easier, and possibly more accurate approach, than using digestible nutrients and chemical contents of grass to predict ME. This set of equations, among all the equations developed in the present study or previously published studies, produced the highest MPE during the internal validation, and may preferably be avoided for grazing cattle. 


\section{Conclusions}

The equations developed in the present study may be applicable to a range of grazing conditions, where pure ryegrass pasture is used, because they have been developed with animals fed fresh-cut grass of a highly diverse quality, and may be used accordingly for different sets of available analyses. The present study highlighted that the use of a combination of chemical composition of grass and nutrient digestibility parameters may improve the accuracy of the prediction of energy concentrations in fresh grass, mainly because the former variables account for the type of nutrient, within the organic matter, that provides the energy. However, the developed equations using GEd or OMd may also be a reliable alternative to predict $\mathrm{ME}$, as indicated by their low prediction errors, and may be recommended instead of equations using DOMD. Similarly, when ME was predicted by using DE as the main predictor, combinations of energy-supplying nutrient contents (EE, WSC and $\mathrm{ADF}$, or $\mathrm{N}$ and $\mathrm{EE}$ ) may be used to improve prediction on a commercial scale. Using DE as the sole predictor for ME contents of grass was a relatively reliable technique and the updated equations formulated in the present study may reduce prediction error, in the case of grazing cattle, when compared with existing equations using solely DE. As implied by the lower prediction errors of the equations developed in the present study, when compared with existing equations used in the US and the UK feeding systems, prediction of DE and ME may be improved by their implementation in animal rationing and routine grass chemical analysis. An under-prediction of $\mathrm{ME}$ for high quality grass (in vivo measured $\mathrm{ME} \geq 12 \cdot 8 \mathrm{MJ} / \mathrm{kg}$ DM) was common for all equations across the studies although this error was slightly reduced in the equations developed in the present study, compared with existing predictions, as illustrated in Bland-Altman plots.

\section{Supplementary material}

To view supplementary material for this article, please visit http://dx.doi.org/10.1017/S0007114515000896

\section{Acknowledgements}

The authors would like to thank colleagues at the Agri-Food and Biosciences Institute (Hillsborough, the UK) for assistance in the collection of experimental data used in the present study.

The authors gratefully acknowledge financial support from the Department of Agriculture, Food and the Marine of the Republic of Ireland under a Research Stimulus Fund Program (11/S/105) and the Department of Agriculture and Rural Development of Northern Ireland. The authors declare no conflicts of interest.

S. S. developed the datasets, performed the statistical analyses, interpreted the data and wrote the manuscript. M. A. advised on and performed the statistical analyses, wrote parts of the 'Materials and methods' section and contributed to the critical review of the 'Materials and methods' and 'Results' sections. X. C. and D. W. collected the experimental data. T. Y. managed the research project, designed and supervised the study and the writing up process, and contributed to the critical review of the manuscript. All authors contributed and approved the final version of the manuscript.

\section{References}

1. O'Donovan M, Lewis E \& O'Kiely P (2011) Requirements of future grass-based ruminant production systems in Ireland. Irish J Agr Food Res 50, 1-21.

2. Ferris C (2007) Sustainable pasture-based dairy systems meeting the challenges. Can J Plant Sci 87, 723-738.

3. Clark DA, Caradus JR, Monaghan RM, et al. (2007) Issues and options for future dairy farming in New Zealand. New Zeal J Agr Res 50, 203-221.

4. Dijkstra J, Kebreab E, Bannink A, et al. (2008) Comparison of energy evaluation systems and a mechanistic model for milk production by dairy cattle offered fresh-grass based diets. Anim Feed Sci Technol 143, 203-219.

5. National Research Council (2001) Nutrient Requirements of Dairy Cattle. Washington, DC: National Academy Press.

6. Agricultural and Food Research Council (1993) Energy and Protein Requirements of Ruminants. An Advisory Manual Prepared by the AFRC Technical Committee on Responses to Nutrients. Wallingford: CAB International.

7. Yan $\mathrm{T} \&$ \& Agnew RE (2004) Prediction of metabolisable energy concentrations from nutrient digestibility and chemical composition in grass silages offered to sheep at maintenance. Anim Feed Sci Technol 117, 197-213.

8. Jarrige R (1989) Ruminant Nutrition: Recommended Allowances and Feed Tables. Paris: Institut National de la Recherche Agronomique \& John Libbey Eurotext.

9. Bruinenberg MH, Zom RLG \& Valk H (2002) Energy evaluation of fresh grass in the diets of lactating dairy cows. Neth J Agr Sci 50, 67-81.

10. Home Office (1986) Animal (Scientific Procedures) Act 1986. London: Her Majesty's Stationery Office.

11. Stergiadis S, Cheng XJ, Allen M, et al. (2015) Evaluating nitrogen utilization efficiency of nonpregnant dry cows offered solely fresh cut grass at maintenance levels. J Anim Sci 93, 709-720.

12. Stergiadis S, Allen M, Chen XJ, et al. (2015) Prediction of nutrient digestibility and energy concentrations in fresh grass using nutrient composition. J Dairy Sci 98, 3257-3273.

13. Yan T \& Mayne CS (2008) Prediction of methane emission of dairy cows offered fresh grass at maintenance level. In Multifunctional Grasslands in a Changing World, p. 143 [Organising Committee of 2008 IGC/IRC Conference, editor]. Guangzhou: Guangdong People's Publishing House.

14. Agnew RE, Park RS \& Mayne CS (2000) The potential of near infrared spectroscopy to predict the chemical and biological characteristics of grazed grass. In Grazing Management: The Principles and Practice of Grazing, for Profit and Environmental Gain, Within Temperate Grassland Systems. Proceedings of the British Grassland Society Conference, 29 February-2 March 2000, Harrogate, pp. 51-52 [A Rook and P Penning, editors]. Kenilworth: British Grassland Society.

15. Agnew RE, Yan T, France J, et al. (2004) Energy requirement and supply. In Feed into Milk: A New Applied Feeding System for Dairy Cows, pp. 11-20 [C Thomas, editor]. Nottingham: Nottingham University Press.

16. International VSN (2013) GenStat for Windows, 16th ed. Hemel Hempstead: VSN International.

17. Robinson DL (1987) Estimation and use of variance components. The Statistician 36, 3-14. 
18. Searle SR, Casella G \& McCulloch CE (1992) Variance Components. New York: John Wiley \& Sons.

19. Yan T, Frost JP, Agnew RE, et al. (2006) Relationships among manure nitrogen output and dietary and animal factors in lactating dairy cows. J Dairy Sci 89, 3981-3991.

20. Givens DI, Everington JM \& Adamson AH (1990) The nutritive value of spring-grown herbage produced on farms throughout England and Wales over four years. III. The prediction of energy values from various laboratory measurements. Anim Feed Sci Technol 27, 185-196.

21. Terry RA, Osbourn DF, Cammell SB, et al. (1974) In vitro digestibility and the estimation of energy in herbage. Vaxtodling 28, 19-25.

22. Australian Agricultural Council (1990) Feeding Standards for Australian Livestock: Ruminants. Melbourne: CSIRO.

23. Yan T, Agnew RE \& Gordon FJ (2002) The combined effects of animal species (sheep versus cattle) and level of feeding on digestible and metabolizable energy concentrations in grass-based diets of cattle. Anim Sci 75, 141-151.
24. Waghorn GC \& Clark DA (2004) Feeding value of pastures for ruminants. New Zeal Vet J 52, 320-331.

25. Wims CM, McEvoy M, Delaby L, et al. (2013) Effect of perennial ryegrass (Lolium perenne L.) cultivars on the milk yield of grazing dairy cows. Animal 7, 410-421.

26. Fanchone A, Noziere P, Portelli J, et al. (2013) Effects of nitrogen underfeeding and energy source on nitrogen ruminal metabolism, digestion, and nitrogen partitioning in dairy cows. I Anim Sci 91, 895-906.

27. Hoekstra NJ, Schulte RPO, Struik PC, et al. (2007) Pathways to improving the $\mathrm{N}$ efficiency of grazing bovines. Eur $J$ Agron 26, 363-374.

28. Van Es AJH (1978) Feed evaluation for ruminants. I. The systems in use from May 1977 onwards in the Netherlands. Livest Prod Sci 5, 331-345.

29. Tas B (2006) Nitrogen utilization of perennial ryegrass in dairy cows. In Fresh Herbage for Dairy Cattle, pp. 125-140 [A Elgersma, J Dijkstra and S Tamminga, editors]. Wageningen: Springer. 